Article

\title{
Propargylated Purine Deoxynucleosides: New Tools for Fluorescence Imaging Strategies
}

\author{
Akkaladevi Venkatesham ${ }^{1}$, Sambasiva Rao Pillalamarri ${ }^{1}$, Flore De Wit ${ }^{2}$, Eveline Lescrinier ${ }^{1}$, \\ Zeger Debyser ${ }^{2}$ and Arthur Van Aerschot $1, *$ (D) \\ 1 Medicinal Chemistry, Rega Institute for Medical Research, Department of Pharmaceutical and \\ Pharmacological Sciences, KU Leuven, Herestraat 49, 3000 Leuven, Belgium; \\ venkat.pallavi2013@gmail.com (A.V.); sambasivarao.iict@gmail.com (S.R.P.); \\ eveline.lescrinier@kuleuven.be (E.L.) \\ 2 Laboratory for Molecular Virology and Gene Therapy, Department of Pharmaceutical and Pharmacological \\ Sciences, KU Leuven, Kapucijnenvoer 33, 3000 Leuven, Belgium; flore.dewit@kuleuven.be (F.D.W.); \\ zeger.debyser@kuleuven.be (Z.D.) \\ * Correspondence: arthur.vanaerschot@kuleuven.be; Tel.: +32-16-372624
}

Academic Editor: Christian Ducho

Received: 12 December 2018; Accepted: 25 January 2019; Published: 28 January 2019

\begin{abstract}
In vivo imaging of biological processes is an important asset of modern cell biology. Selectively reacting fluorophores herein are an important tool and click chemistry reactions take a large share in these events. 5-Ethynyl-2'-deoxyuridine (EdU) is well known for visualizing DNA replication, but does not show any selectivity for incorporation into DNA. Striving for specific visualization of virus replication, in particular HIV replication, a series of propargylated purine deoxynucleosides were prepared aiming for selective incorporation by HIV reverse transcriptase (RT). We here report on the synthesis and preliminary biological effects (cellular toxicity, HIV inhibitory effects, and feasibility of the click reaction) of these nucleoside analogues.
\end{abstract}

Keywords: click reaction; propargylated nucleosides; imaging; DNA visualization; fluorophores; ethynyl-2'-deoxyuridine (EdU); HIV toxicity; Mitsunobu reaction

\section{Introduction}

Visualization of biological processes via labeling of DNA or proteins using specific fluorescent markers has become a cornerstone of many cell biology studies. The standard methodologies herein use monoclonal antibodies either recognizing incorporated 5-bromo-2'-deoxyuridine (BrdU) for DNA studies or modified amino acids for proteins, where the antibodies are functionalized to provide a fluorescent signal. Many alternative strategies have been used, among which the use of thiol reactive probes for direct protein visualization and many other alternatives. Two excellent handbooks on molecular probes and fluorescence imaging provide a complete overview of all fluorescent labeling techniques $[1,2]$.

A very different approach makes use of green fluorescent protein and its many variants, which can be used to genetically engineer specific proteins or organisms. For instance, this way retroviral replication was visualized for the first time in living cells [3]. This nice methodology, however, does not provide the means to selectively visualize replication of wild type viruses.

An alternative to fluorescence imaging to allow for visual understanding of biological processes within a living organism, is the use of bioluminescent imaging (BLI). BLI uses light emitted from luciferase-expressing bioreporter cells and its main use is the in vivo tracking of cell fate or the study of regulation of gene expression via reporter gene expression, which, however, is not the topic of our work [4]. 
As described above, analysis of DNA synthesis in the past was mainly based on incorporation of BrdU, which is detected based on recognition by specific antibodies, but requiring prior treatment of the samples to allow reaction of the incorporated BrdU with the antibodies [5,6]. In contrast, detection of replicational activity in vivo was accomplished for the first time in 2008, making use of 5-ethynyl-2'-deoxyuridine (EdU, 1) [7]. The triple bond containing nucleoside incorporated well into growing DNA chains and allowed visualization of the latter, introducing fluorescent markers via click chemistry. Several small fluorescent azides hereto proved able to penetrate preparations of tissue and organ explants and to provide the well-known $\mathrm{Cu}(\mathrm{I})$-catalyzed cycloaddition reaction. The method proved very popular, and a large number of studies in the past have focused on measuring the rate of mitochondrial DNA (mtDNA) replication, with S. Lentz et al. being the first to use EdU to visualize mtDNA biogenesis [8]. Its close analogue, 5-ethynyl-2'-deoxycytidine (EdC, 2) likewise was developed as marker of cellular replication activity proving less cytotoxic [9]. However, Ligasova et al. more recently demonstrated that EdC is metabolized and incorporated into DNA as EdU, with toxicity being related to the extent of its total incorporation [10].

EdU (and EdC) being valuable compounds for in vivo analyses of DNA replication, are recognized and incorporated into DNA by various polymerases, and therefore lack the required selectivity for in vivo visualization of viral replication. Indeed, EdU is well incorporated by the host mitochondrial DNA polymerase provoking high off-target labeling of the cytoplasm and secondly, it is impossible to discriminate viral DNA in the nucleus due to the incorporation of the functionalized nucleoside by the host DNA polymerase. To develop virus-specific chromophores, the clickable nucleosides should not be recognized by the cellular DNA polymerases, but selectively incorporated by the viral polymerase. We therefore opted for a series of propargylated nucleosides, whilst aiming in the first place for the selective incorporation into HIV viral DNA and lowering the off-target labeling of cellular DNA. The choice for propargyl moieties was dictated as a compromise in the following trade-off: having a small distance between the triple bond and the heterocycle should allow the click reaction to run smoothly, while having too long extensions on the nucleosides potentially could hamper their functionalization into the required triphosphates to allow incorporation into DNA. In addition, the propargyl alcohol and amine are cheaply available materials. The ultimate goal of this project was the visualization of replicating single particles. Indeed, double-stranded copy DNA (cDNA) is produced by the viral reverse transcriptase (RT). This cDNA is subsequently integrated into the host chromosome by the viral integrase (IN). Using an engineered virus containing a GFP-modified integrase (IN-eGFP), we at present can identify single viral complexes in infected cells [11], but we are unable to identify whether they contain reverse transcribed DNA, nor can this technique be used for visualization of wild type viruses.

A series of seven propargylated deoxynucleosides (Figure 1, 3-10) were conceived, synthesized, and evaluated for their cell cytotoxic and HIV antiviral effects in a preliminary effort to obtain a clickable nucleoside analogue, which would be selectively incorporated into HIV-DNA. Only a few propargyl-containing purine nucleosides have been described before. Introducing the propargyl moiety on the 2-amine position of dG providing $N^{2}$-(2-propyn-1-yl)-2'-deoxyguanosine (11) does not look very appealing as it most probably will disturb base pairing [12]. However, also the purine analogues 5 and $\mathbf{8}$ were described by the same authors albeit to provide clickable nucleosides for incorporation of boron clusters into DNA using pre-functionalized phosphoramidites. In addition, we unintentionally obtained 10 almost exclusively upon alkylation of 2 '-deoxyinosine (dI) under Mitsunobu conditions. Finally, the 8-propargylamino substituted adenosine 12, being the ribose analogue of 3, was already prepared in the past to introduce a clickable Rhodamine dye [13]. 

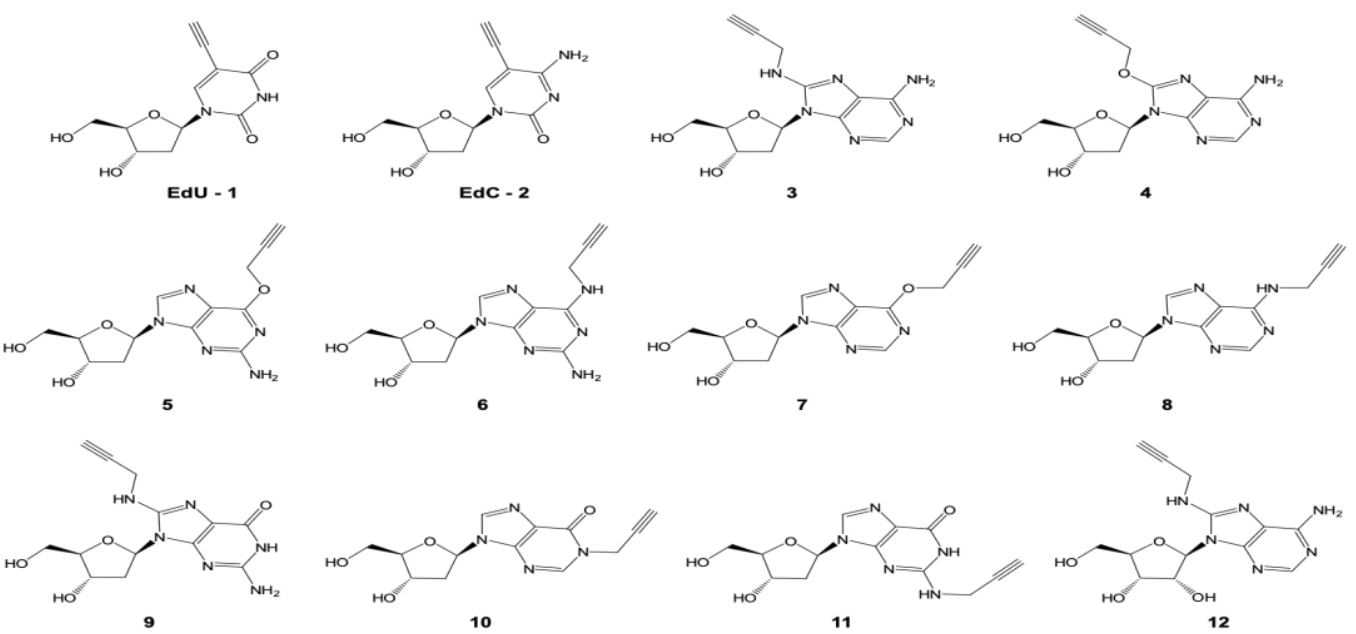

Figure 1. Structures of the envisaged propargyl containing purine 2 -deoxynucleosides for visualization studies (3-10), along with well-known 5-Ethynyl-2'-deoxyuridine (EdU) (1) and 5-ethynyl-2'-deoxycytidine $(\mathrm{EdC})(2)$ and two literature described propargyl modified purine derivatives (11-12).

\section{Results}

\subsection{Chemistry}

The synthesis of 8-propynylamino-(3) and 8-propynyloxy-2'-deoxyadenosine (4) involves the formation of a carbon-hetero bond at the C8 position of the nucleobase. The latter is commonly achieved using nucleophilic substitution on the 8-brominated derivative (Scheme 1, 13). Synthesis of 4 required prior protection of both hydroxyl moieties as tert-butyldimethylsilyl (TBDMS) ethers using TBDMSCl and imidazole in dry dimethylformamide (DMF) at $\mathrm{rt}$ for $24 \mathrm{~h}$, affording 14 in $81 \%$ yield. Nucleophilic substitution of the 8-bromine with propargyl alcohol was accomplished using nBuLi in tetrahydrofuran (THF) at $-40{ }^{\circ} \mathrm{C}$ to $\mathrm{rt}$ for $24 \mathrm{~h}$ affording 15 in $91 \%$ yield [14]. Deprotection of both silyl groups using tetrabutylammonium fluoride (TBAF) in THF at $\mathrm{rt}$ for $3 \mathrm{~h}$ furnished 4 in $85 \%$ yield. Direct substitution with propargyl amine in presence of $\mathrm{CaCO}_{3}$ in $\mathrm{EtOH}$ at $70-80{ }^{\circ} \mathrm{C}$ for $14 \mathrm{~h}$ gave 3 in $72 \%$ yield [13].

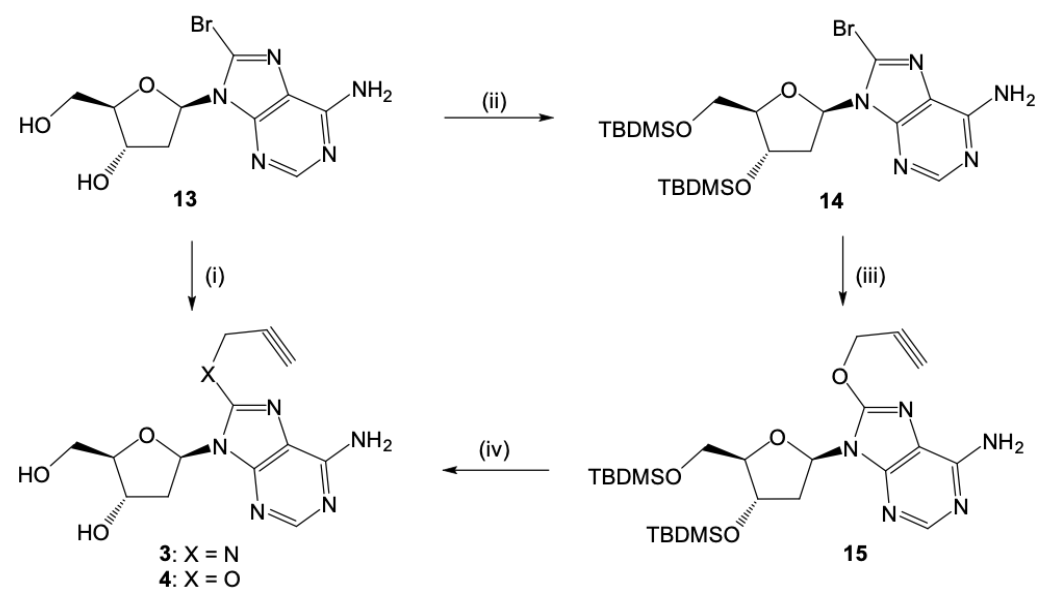

Scheme 1. (i) Propargylamine, $\mathrm{CaCO}_{3}, \mathrm{EtOH}, 70-80{ }^{\circ} \mathrm{C}, 14 \mathrm{~h}$ (72\% of 3); (ii) TBDMSCl, imidazole, dry DMF, rt, $24 \mathrm{~h}(81 \%)$; (iii) propargylalcohol, $n \mathrm{BuLi}, \mathrm{THF},-40{ }^{\circ} \mathrm{C}$ to rt, $24 \mathrm{~h}$ (91\%); (iv) TBAF, THF, rt, $3 \mathrm{~h}$ $(85 \%$ of 4$)$.

C8-modification of 2'-deoxyguanosine to provide 9 was less straightforward, as complexation of the palladium catalyst by interaction through $O^{6}$ and $N^{7}$ positions of the nucleobase was suggested 
to cause the poor reactivity of guanosine towards palladium catalyzed cross-coupling reactions [15]. To inhibit the complexation of metals by guanosine derivatives, the $O^{6}$ position was protected as a TMS-ether. This fully protected dG-derivative was synthesized starting with bromination of 16 with N-bromosuccinimide (NBS) [16] in a (1:4) $\mathrm{H}_{2} \mathrm{O}: \mathrm{CH}_{3} \mathrm{CN}$ mixture in good yield (Scheme 2). The $5^{\prime}$ - and $3^{\prime}$-hydroxyl groups of $\mathbf{1 7}$ were protected as TBDMS ethers to give 18 in $87 \%$ yield, while the TMS ether group was introduced at $\mathrm{O}^{6}$-position by Mitsunobu reaction involving 2-TMS-ethanol, diisopropyl azodicarboxylate (DIAD) and triphenyl phosphine (TPP) in dioxane at $40{ }^{\circ} \mathrm{C}$ for $24 \mathrm{~h}$ to afford 19 in $65 \%$ yield. The exocyclic amine was protected by treatment with isobutyryl chloride in pyridine at $\mathrm{rt}$ for $3 \mathrm{~h}$ to give the key intermediate 20 in 85\% yield. Buchwald-Hartwig amination [17] of 20 using propargyl amine in presence of $\mathrm{Pd}_{2}(\mathrm{dba})_{3}, 2,2^{\prime}$-bis(diphenylphosphino)-1,1'-binaphthyl (BINAP) and $\mathrm{Cs}_{2} \mathrm{CO}_{3}$ in dioxane at $100{ }^{\circ} \mathrm{C}$ for $14 \mathrm{~h}$ furnished 21 in $61 \%$ yield. Finally, all three silyl moieties can be removed in a single deprotection step using TBAF in THF, followed by deprotection of the isobutyryl group using $7 \mathrm{~N} \mathrm{NH}_{3}$ in $\mathrm{MeOH}$ at $60{ }^{\circ} \mathrm{C}$ for $14 \mathrm{~h}$ to obtain the final compound 9 in $65 \%$ yield. Use of $N^{2}$-Boc protection instead proved inappropriate, leading to depurination during the final deprotection step with $90 \%$ aq. TFA at rt for $14 \mathrm{~h}$. Likewise, introduction of an 8-propynyloxy moiety on compound 20 proved unsuccessful under Buchwald-Hartwig [18] conditions. Attempts using either propargyl alcohol, $\mathrm{Pd}_{2}(\mathrm{dba})_{3}, \mathrm{t}$-BuDavePhos, $\mathrm{Cs}_{2} \mathrm{CO}_{3}$, dioxane at $100{ }^{\circ} \mathrm{C}$ or $\mathrm{Pd}_{2}(\mathrm{dba})_{3}, \mathrm{t}$-BuDavePhos, $\mathrm{K}_{3} \mathrm{PO}_{4}$, toluene at $100{ }^{\circ} \mathrm{C}$ led to degradation of the starting material.

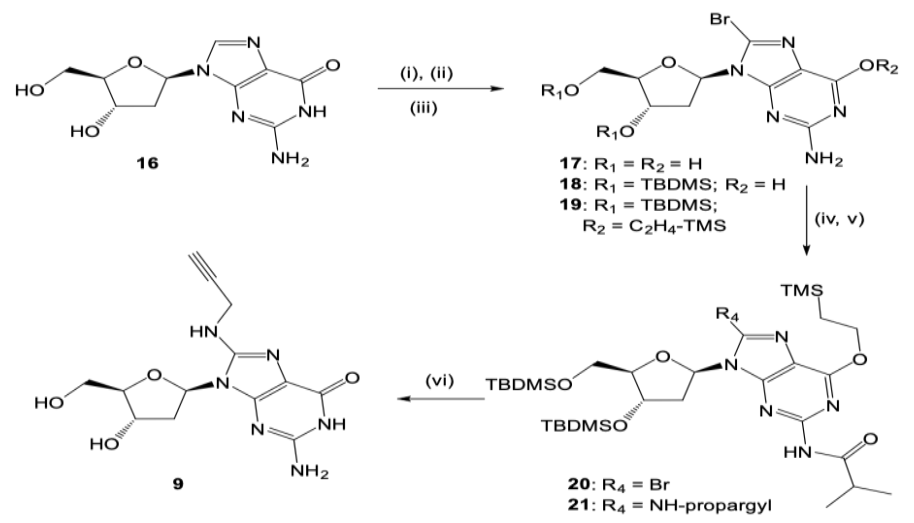

Scheme 2. (i) N-bromosuccinimide (NBS), $\mathrm{CH}_{3} \mathrm{CN}: \mathrm{H}_{2} \mathrm{O}$, rt, $45 \mathrm{~min}$ (91\% of 17); (ii) TBDMSCl, imidazole, dry DMF, rt, $14 \mathrm{~h}$ (87\% of 18); (iii) 2-TMS-ethanol, TPP, diisopropyl azodicarboxylate (DIAD), 1,4 dioxane, $40{ }^{\circ} \mathrm{C}, 24 \mathrm{~h}(65 \%)$; (iv) isobutyryl chloride, anh. pyridine $0{ }^{\circ} \mathrm{C}$ to $\mathrm{rt}, 3 \mathrm{~h}(85 \%)$; (v) propargyl amine, $\mathrm{Pd}_{2}(\mathrm{dba})_{3}, \operatorname{racBINAP}, \mathrm{Cs}_{2} \mathrm{CO}_{3}, 100{ }^{\circ} \mathrm{C}, 14 \mathrm{~h}(61 \%)$; (vi) TBAF, THF, rt, $14 \mathrm{~h} ; 7 \mathrm{~N}$ $\mathrm{NH}_{3}$ in $\mathrm{MeOH}, 60^{\circ} \mathrm{C}, 14 \mathrm{~h}$ ( $65 \%$ of 9 overall for two steps).

Synthesis of the deoxyguanosine analogues 5 and 6 requires introduction of the carbon-hetero bond at the C6 position of the nucleobase. This is commonly achieved using either Mitsunobu [19] or nucleophilic substitution [20] reactions as shown in Scheme 3. Hereto, 16 was reacted with TBDMSCl, imidazole in DMF at rt for $24 \mathrm{~h}$ to give 22 in $84 \%$ yield. The propynyl moiety was then introduced at $\mathrm{O}^{6}$ by Mitsunobu reaction involving propargyl alcohol, DIAD and TPP in dioxane at $\mathrm{rt}$ for $14 \mathrm{~h}$ to give 23 in 49\% yield, while a propynylamino moiety was introduced at C6 following activation of 22 at 6-OH position with 2,4,6- triisopropylbenzenesulfonyl chloride (TIBSCl), DMAP and $\mathrm{NEt}_{3}$ in DCM at rt for $48 \mathrm{~h}$. Subsequent nucleophilic substitution with propargyl amine in EtOH at $70-80{ }^{\circ} \mathrm{C}$ for $24 \mathrm{~h}$ afforded the 2,6-diaminopurine derivative 124 in 55\% (combined yield). Deprotection of both silyl moieties using TBAF in THF at rt for $2 \mathrm{~h}$ for 23 afforded 5 in 85\% yield, while 24 was deprotected using $\mathrm{NH}_{4} \mathrm{~F}$ in $\mathrm{MeOH}$ at $70-80{ }^{\circ} \mathrm{C}$ for $24 \mathrm{~h}$ providing the diaminopurine 6 in $81 \%$ yield. 


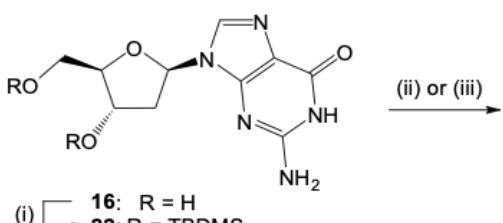

(i) $\square$ 16: $R=H$

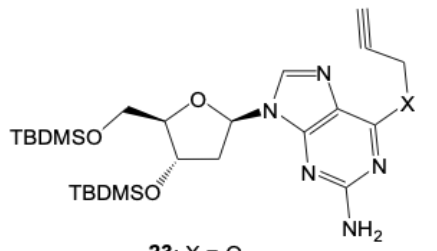

23: $X=O$
24: $X=N$

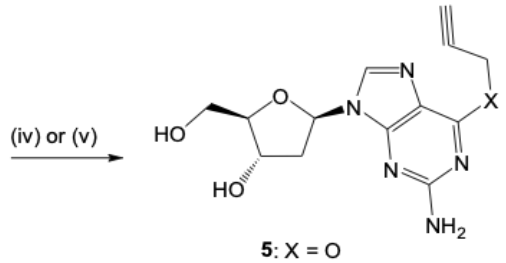

5: $X=O$
6: $X=N$

Scheme 3. (i) TBDMSCl, imidazole, DMF, rt, 24 h (84\%); (ii) propargyl alcohol, TPP, DIAD, dioxane, rt, $14 \mathrm{~h}$ (49\% of 23); (iii) TIBSCl, $\mathrm{Et}_{3} \mathrm{~N}$, cat DMAP, DCM, 48 h; propargylamine, $\mathrm{EtOH}$, glass sealed tube, $100{ }^{\circ} \mathrm{C}, 14 \mathrm{~h}$ (55\% overall for both steps to 24); (iv) TBAF, THF, rt, $2 \mathrm{~h}$ (85\% of 5); (v) $\mathrm{NH}_{4} \mathrm{~F}, \mathrm{MeOH}$, $70-80{ }^{\circ} \mathrm{C}, 24 \mathrm{~h},(81 \%$ of 6$)$.

Synthesis of the C6-modified 2'-deoxypurine analogues $\mathbf{7}$ and $\mathbf{8}$ was attempted analogously to the $2^{\prime}-\mathrm{dG}$ congeners via either Mitsunobu reaction or nucleophilic substitution reaction at $\mathrm{C} 6$ on $\mathrm{dI}(25)$ as shown in Scheme 4. Protection of $\mathbf{2 5}$ with TBDMSCl, imidazole in DMF at rt for $24 \mathrm{~h}$ afforded 26 in $78 \%$ yield. Alkylation under Mitsunobu conditions afforded almost exclusively the $N^{1}$-propargylated dI analogue 29, which was deprotected with ammonium fluoride affording 10. Only using 2D NMR, the undesired structure was unequivocally determined (see below). The propargyl moiety was selectively introduced at the O6-position [21] via reaction with $\mathrm{BOP}$ and $\mathrm{Cs}_{2} \mathrm{CO}_{3}$ followed by treatment of the BOP adduct with propargyl alcohol and additional $\mathrm{Cs}_{2} \mathrm{CO}_{3}$ affording 27 in $91 \%$. The $\mathrm{O}^{6}$-propargylated (7) and N1-propargyl deoxyinosine (10) derivatives were distinguished based on 2D NMR (HMBC) via propargyl $\mathrm{CH}_{2}$ correlation with the $\mathrm{C} 2$ and $\mathrm{C} 6$ carbons. The $\mathrm{CH}_{2}$ protons of $\mathbf{1 0}$ proved strongly correlated with both $\mathrm{C} 2$ and $\mathrm{C} 6$ indicating propargylation at $N^{1}$, whereas $\mathrm{CH}_{2}$ protons of 7 are strongly correlated only with $\mathrm{C} 6$ indicative for propargylation at $\mathrm{O}^{6}$-position. The ${ }^{1} \mathrm{H}-\mathrm{NMR}$ signal for $\mathrm{NCH}_{2}$ appeared at higher field than anticipated at $4.89 \mathrm{ppm}$, whereas signal for $\mathrm{OCH}_{2}$ appeared in the range low filed at $5.28 \mathrm{ppm}$. Finally, the propynylamino moiety was introduced at $\mathrm{C} 6$ following activation of 23 with TIBSCl, DMAP, and $\mathrm{NEt}_{3}$ in DCM at rt for $48 \mathrm{~h}$, and nucleophilic aromatic substitution with propargyl amine, EtOH at $70-80{ }^{\circ} \mathrm{C}$ for $24 \mathrm{~h}$ to furnish $\mathbf{2 8}$ in $57 \%$. Deprotection of $\mathbf{2 7 - 2 9}$ using $\mathrm{NH}_{4} \mathrm{~F}$ in $\mathrm{MeOH}$ at $70-80^{\circ} \mathrm{C}$ for $24 \mathrm{~h}$ afforded 7,8 , and 10 in $71 \%, 75 \%$ and $80 \%$, respectively.<smiles>O=c1[nH]cnc2c1ncn2C1CC(O)C(CO)O1</smiles><smiles>[10BH2][13CH2]</smiles>

(i) $\square$ 26: $R=$ TBDMS<smiles>[X]c1ncnc2c1ncn2[C@@H]1C[C@@H]([Y20])[C@@H](CO)O1</smiles>

(ii)<smiles>[2H]CC1CC(n2cnc3c(=O)n(CC#C)cnc32)OC1[2H]</smiles>

(v) $\square$ 29: $R=$ TBDMS

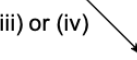

(v)

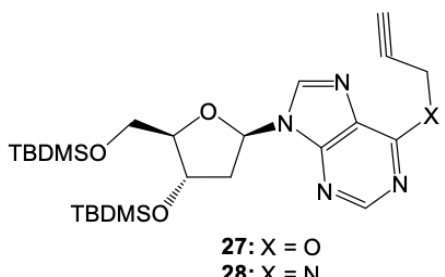

28: $X=N$

Scheme 4. (i) TBDMSCl, imidazole, DMF, rt, 24 h (92\%); (ii) propargyl alcohol, TPP, DIAD, THF, rt, $14 \mathrm{~h}$ (78\% of 29); (iii) BOP, $\mathrm{Cs}_{2} \mathrm{CO}_{3}$, propargyl alcohol, THF, rt, $5 \mathrm{~h}$ (91\% of 27); (iv) TIBSCl, Et 3 N, cat DMAP, DCM, 48 h; Propargyl amine, EtOH, glass sealed tube, $100{ }^{\circ} \mathrm{C}, 14 \mathrm{~h}(57 \%$ overall for both steps to 28); (v) $\mathrm{NH}_{4} \mathrm{~F}, \mathrm{MeOH}, 70-80{ }^{\circ} \mathrm{C}, 24 \mathrm{~h}(71 \%, 75 \%$ and $80 \%$, respectively for 7,8 and 10). 


\subsection{Biological Properties}

Having obtained the desired propargylated 2'-deoxynucleosides, their cytotoxicity and potential antiviral effect was determined based on reduction of the yellow colored 3-(4,5-dimethylthiazol-2-yl)-2,5-diphenyltetrazolium bromide (MTT) by mitochondrial dehydrogenase of metabolically active MT-4 cells to a blue formazan derivative [22]. In contrast to EdU, which shows quite cytotoxic, none of the various congeners displayed any remarkable toxic effect nor HIV inhibition (Table 1), paving the way for further evaluation of their selectivity for visualization of viral replication through click chemistry. The use of the MTT assay is appropriate as it is a standard assay to test for cell toxicity and HIV-1 inhibition after multiple rounds of replication (day 5). We also tested the effect on HIV-1 infection in single round (HIV-1 fLuc readout). Also here only EdU showed a major reduction of HIV-1 infection (not shown). The selectivity was examined in vitro with a primer extension assay comparing incorporation of the analogues by human DNA polymerase $\alpha$, human mitochondrial DNA polymerase $\gamma$ and HIV-1 reverse transcriptase and will be communicated elsewhere (De Wit et al., unpublished data).

Table 1. Cell viability and HIV inhibition assay as determined in MT4-cells.

\begin{tabular}{ccc}
\hline Analogue & $\mathrm{CC}_{\mathbf{5 0}}(\boldsymbol{\mu M})$ & $\mathrm{EC}_{\mathbf{5 0}}(\mu \mathrm{M})$ \\
\hline $\mathbf{1}(\mathrm{EdU})$ & $=2.2 \pm 1.3$ & $>2.2$ \\
\hline $\mathbf{3}$ & $>200$ & $>200$ \\
$\mathbf{4}$ & $>600$ & $>600$ \\
$\mathbf{5}$ & $>600$ & $>600$ \\
$\mathbf{6}$ & $>50$ & $>50$ \\
7 & $>1000$ & $>1000$ \\
$\mathbf{8}$ & $>1000$ & $>1000$ \\
$\mathbf{9}$ & $>600$ & $>600$ \\
$\mathbf{1 0}$ & $>600$ & $>600$ \\
\hline
\end{tabular}

For preliminary visualization experiments, cells were treated with the newly synthesized propargylated analogues or EdU (1) as a control, followed by staining for cytochrome C (mitochondrial staining) together with the click reaction using the Click-iT EdU Alexa Fluor 647 imaging kit (Thermo Fisher Scientific Inc., Waltham, MA, USA). Visualization was done using confocal microscopy (Figure 2A at top for EdU, at bottom for 5). In parallel, DAPI (4',6-diamidino-2-phenylindole, binding to AT-rich regions) was used for nuclear staining. Remarkably, analogue 5 resulted in a clear, almost selective mitochondrial staining, as shown by co-localization with cytochrome C (Figure 2A, bottom, panel D). No nuclear staining is seen (absence of fluorescence in the DAPI stained region) in contrast with EdU.

In another experiment, using IN-eGFP [11], co-localization of both fluorescence signals resulting from the click reaction and the HIV-integrase protein, respectively, will indicate the selectivity of the various compounds for cDNA labeling. As shown in Figure 2B, the same propargylated analogue 5 afforded co-localization signals with the IN-eGFP virus, but analysis was hampered as of the ubiquitous mitochondrial staining. Full biological evaluation of all analogues will be reported elsewhere. 
A
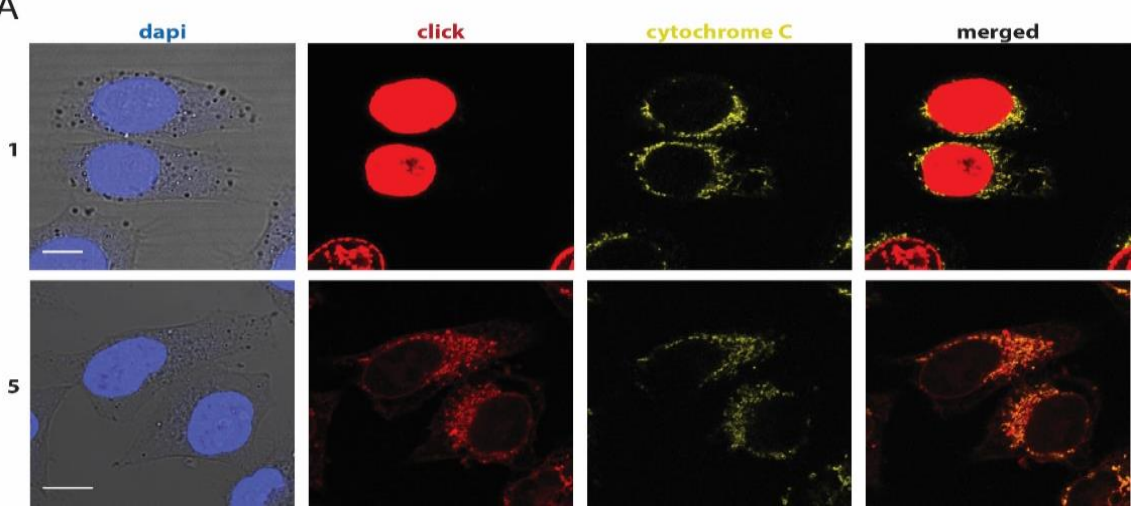

B
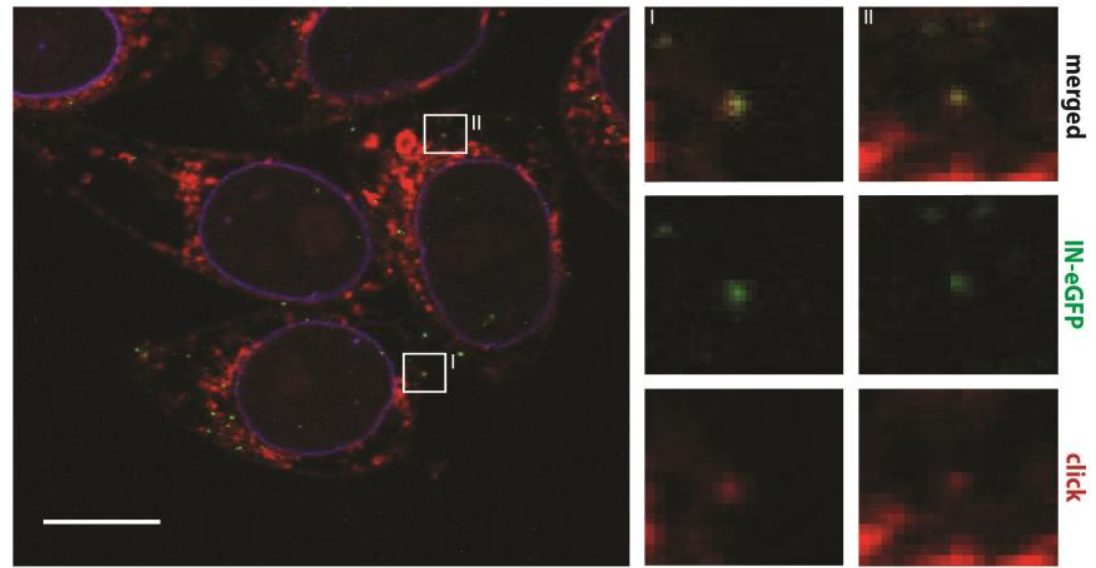

Figure 2. Localization of the click signal for compound 5, showing predominantly incorporation into mitochondrial DNA (panel A) and co-localization with the HIV-integrase protein (panel B).

\section{Materials and Methods}

All ${ }^{1} \mathrm{H}$ and ${ }^{13} \mathrm{C}$-NMR spectra and MS analytical spectra are available online, see Supplementary Materials.

\subsection{Chemistry}

\subsubsection{8-Bromo-3', $5^{\prime}$-O-bis(tert-butyldimethylsilyl)-2' deoxyadenosine (14)}

To a stirred solution of 8-bromo-2'-deoxyadenosine 13 (0.300 g, $0.909 \mathrm{mmol})$ in dry DMF (15 mL) was added imidazole $(0.371 \mathrm{~g}, 5.45 \mathrm{mmol})$, dimethylaminopyridine ( $30 \mathrm{mg}, 0.25 \mathrm{mmol})$ and TBDMSCl $(0.411 \mathrm{~g}, 2.72 \mathrm{mmol})$ at $\mathrm{rt}$ under $\mathrm{N}_{2}$ atm. After stirring for $24 \mathrm{~h}$, water $(30 \mathrm{~mL})$ and EtOAc $(30 \mathrm{~mL})$ were added. The aqueous phase was extracted with EtOAc $(3 \times 30 \mathrm{~mL})$, and the combined organic phases were dried $\left(\mathrm{Na}_{2} \mathrm{SO}_{4}\right)$, filtered, and the solvent was removed in vacuo. The residue was purified by column chromatography on silica gel (hexane:EtOAc $=6: 4)$ and afforded $14(0.412 \mathrm{~g}, 81 \%)$ as a white solid. ${ }^{1} \mathrm{H}-\mathrm{NMR}\left(300 \mathrm{MHz}, \mathrm{CDCl}_{3}\right) \delta 8.27(\mathrm{~s}, 1 \mathrm{H}, \mathrm{H} 2), 6.37\left(\mathrm{t}, J=6.7 \mathrm{~Hz}, 1 \mathrm{H}, \mathrm{H1} 1^{\prime}\right), 5.69$ (brs, 2H, $\mathrm{NH}_{2}$ ), $4.89\left(\mathrm{dd}, J=9.4,3.8 \mathrm{~Hz}, 1 \mathrm{H}, \mathrm{H} 3^{\prime}\right), 4.03-3.87\left(\mathrm{~m}, 2 \mathrm{H}, \mathrm{H} 4^{\prime}, \mathrm{H}^{\prime}{ }^{\prime} \mathrm{a}\right), 3.75-3.62\left(\mathrm{~m}, 2 \mathrm{H}, \mathrm{H} 5^{\prime} \mathrm{b}, \mathrm{H} 2^{\prime} \mathrm{a}\right), 2.25$ (ddd, $\left.J=13.1,7.0,4.3 \mathrm{~Hz}, 1 \mathrm{H}, \mathrm{H} 2^{\prime} \mathrm{b}\right), 0.96\left(\mathrm{~s}, 9 \mathrm{H}, \mathrm{SiC}\left(\mathrm{CH}_{3}\right)_{3}\right), 0.85\left(\mathrm{~s}, 9 \mathrm{H}, \mathrm{SiC}\left(\mathrm{CH}_{3}\right)_{3}\right), 0.16\left(\mathrm{~s}, 6 \mathrm{H}, \mathrm{Si}\left(\mathrm{CH}_{3}\right)_{2}\right)$, $0.02\left(\mathrm{~s}, 3 \mathrm{H}, \mathrm{SiCH}_{3}\right),-0.02\left(\mathrm{~s}, 3 \mathrm{H}, \mathrm{SiCH}_{3}\right) ;{ }^{13} \mathrm{C}-\mathrm{NMR}\left(75 \mathrm{MHz}_{2} \mathrm{CDCl}_{3}\right) \delta 153.9,152.2,150.6,127.9,120.2$, 87.4, 86.0, 72.0, 62.3, 36.4, 25.5, 18.0, 17.7, $-5.0,-5.0,-5.8,-5.8$; HR-ESI MS $(m / z):[\mathrm{M}+\mathrm{H}]^{+}$calculated for $\mathrm{C}_{22} \mathrm{H}_{41} \mathrm{BrN}_{5} \mathrm{O}_{3} \mathrm{Si}_{2}$, 558.1926; found 558.1929 [23]. 


\subsection{2. $3^{\prime}, 5^{\prime}$-O-Bis(tert-butyldimethylsilyl)-8-propynyloxy-2'deoxyadenosine (15)}

Compound $14(0.300 \mathrm{~g}, 0.537 \mathrm{mmol})$ was dissolved in anhydrous THF $(15 \mathrm{~mL})$ in a round bottom flask under Ar atm. In a separate reaction flask fitted with balloon, propargyl alcohol $(0.53 \mathrm{~mL}$, $9.14 \mathrm{mmol})$ was added to freshly distilled THF $(10 \mathrm{~mL})$ and the solution was kept under $\mathrm{N}_{2} \mathrm{~atm}$ and cooled down to $-40^{\circ} \mathrm{C}$. Then, $n$-BuLi $(2.5 \mathrm{~mL}$ of a $2.5 \mathrm{M}$ hexane solution, $6.44 \mathrm{mmol})$ was gradually added to the latter reaction mixture; the by-product butane was collected in the balloon. The reaction was completed instantly. This in situ generated lithium propargyloxide was transferred to the flask containing 14 through an oven-dried syringe. Progress of the reaction at rt was monitored by TLC. After $24 \mathrm{~h}$, the solution was neutralized by dilute acetic acid. Excess solvent was removed under reduced pressure and the solid residue was then partitioned between water $(50 \mathrm{~mL})$ and EtOAc $(50 \mathrm{~mL})$. The layers were separated and the aqueous layer was extracted with EtOAc $(3 \times 50 \mathrm{~mL})$. The combined organic layers were washed with brine $(50 \mathrm{~mL})$, dried $\left(\mathrm{Na}_{2} \mathrm{SO}_{4}\right)$ and concentrated in vacuo and purified by flash column chromatography (hexane:EtOAc $=10: 1)$ affording $15(0.260 \mathrm{~g}, 91 \%)$ as a brown semisolid. ${ }^{1} \mathrm{H}-\mathrm{NMR}\left(300 \mathrm{MHz}, \mathrm{CDCl}_{3}\right) \delta 8.21(\mathrm{~s}, 1 \mathrm{H}, \mathrm{H} 2), 6.35\left(\mathrm{t}, J=6.9 \mathrm{~Hz}, 1 \mathrm{H}, \mathrm{H1}^{\prime}\right), 5.76(\mathrm{~d}$, $\left.J=4.4 \mathrm{~Hz}, 2 \mathrm{H}, \mathrm{NH}_{2}\right), 5.11\left(\mathrm{~d}, J=2.5 \mathrm{~Hz}, 2 \mathrm{H}, \mathrm{OCH}_{2}\right), 4.73\left(\mathrm{dt}, J=6.4,3.5 \mathrm{~Hz}, 1 \mathrm{H}, \mathrm{H}^{\prime}\right), 3.93(\mathrm{ddd}, J=6.9$, 4.9, 3.2 Hz, $\left.1 \mathrm{H}, \mathrm{H} 4^{\prime}\right), 3.84\left(\mathrm{dd}, J=10.6,6.9 \mathrm{~Hz}, 1 \mathrm{H}, \mathrm{H}^{\prime}{ }^{\prime} \mathrm{a}\right), 3.69\left(\mathrm{dd}, J=10.6,5.0 \mathrm{~Hz}, 1 \mathrm{H}, \mathrm{H} 5^{\prime} \mathrm{b}\right), 3.31(\mathrm{dt}$, $\left.J=13.1,6.5 \mathrm{~Hz}, 1 \mathrm{H}, \mathrm{H2}{ }^{\prime} \mathrm{a}\right), 2.61(\mathrm{t}, J=2.4 \mathrm{~Hz}, 1 \mathrm{H}, \mathrm{CH}), 2.18\left(\mathrm{ddd}, J=13.1,6.9,3.7 \mathrm{~Hz}, 1 \mathrm{H}, \mathrm{H} 2^{\prime} \mathrm{b}\right), 0.93$ (s, 9H, $\left.\mathrm{SiC}\left(\mathrm{CH}_{3}\right)_{3}\right), 0.86\left(\mathrm{~s}, 9 \mathrm{H}, \mathrm{SiC}\left(\mathrm{CH}_{3}\right)_{3}\right), 0.13\left(\mathrm{~s}, 6 \mathrm{H}, \mathrm{Si}\left(\mathrm{CH}_{3}\right)_{2}\right), 0.01\left(\mathrm{~d}, J=6.2 \mathrm{~Hz}, 6 \mathrm{H}, \mathrm{Si}\left(\mathrm{CH}_{3}\right)_{2}\right)$; ${ }^{13} \mathrm{C}-\mathrm{NMR}\left(75 \mathrm{MHz}, \mathrm{CDCl}_{3}\right) \delta$ 153.4, 153.1, 150.8, 149.6, 115.3, 87.1, 82.2, 76.7, 76.1, 72.3, 62.8, 57.2, 36.4, 25.6, 25.5, 18.0, 17.7, -5.0, -5.1, -5.7, -5.8; HR-ESI MS $(m / z):[\mathrm{M}+\mathrm{H}]^{+}$calculated for $\mathrm{C}_{25} \mathrm{H}_{44} \mathrm{~N}_{5} \mathrm{O}_{4} \mathrm{Si}_{2}$, 534.2926; found 534.2931.

\subsubsection{8-Propynyloxy-2'-deoxyadenosine (4)}

To a stirred solution of $\mathbf{1 5}(0.250 \mathrm{~g}, 0.47 \mathrm{mmol})$ in anh.THF $(10 \mathrm{~mL})$ was added TBAF (1M in THF) $(1.87 \mathrm{~mL}, 1.87 \mathrm{mmol})$ at $\mathrm{rt}$ under $\mathrm{N}_{2}$ atm. After reaction for $3 \mathrm{~h}$, the solvent was removed in vacuo, and the residue was purified by flash column chromatography on silica gel $(\mathrm{MeOH}: \mathrm{DCM}=1: 9)$ to give the title compound $4(0.121 \mathrm{~g}, 85 \%)$ as a white solid. ${ }^{1} \mathrm{H}-\mathrm{NMR}(300 \mathrm{MHz}, \mathrm{MeOD}) \delta 8.06(\mathrm{~s}, 1 \mathrm{H}, \mathrm{H}-2), 6.36$ $\left(\mathrm{dd}, J=8.5,6.3 \mathrm{~Hz}, 1 \mathrm{H}, \mathrm{H} 1^{\prime}\right), 5.19\left(\mathrm{~d}, J=2.4 \mathrm{~Hz}, 2 \mathrm{H}, \mathrm{OCH}_{2}\right), 4.63-4.58\left(\mathrm{~m}, 1 \mathrm{H}, \mathrm{H3} 3^{\prime}\right), 4.06(\mathrm{dd}, J=5.1$, $\left.3.0 \mathrm{~Hz}, 1 \mathrm{H}, \mathrm{H} 4^{\prime}\right), 3.91-3.70\left(\mathrm{~m}, 2 \mathrm{H}, \mathrm{H} 5^{\prime}\right), 3.17(\mathrm{t}, J=2.4 \mathrm{~Hz}, 1 \mathrm{H}, \mathrm{CH}), 2.98(\mathrm{ddd}, J=14.3,8.5,5.8 \mathrm{~Hz}$, $\left.1 \mathrm{H}, \mathrm{H} 2^{\prime} \mathrm{a}\right), 2.27$ (ddd, $\left.J=13.4,6.3,2.0 \mathrm{~Hz}, 1 \mathrm{H}, \mathrm{H2}{ }^{\prime} \mathrm{b}\right) ;{ }^{13} \mathrm{C}-\mathrm{NMR}(75 \mathrm{MHz}, \mathrm{MeOD}) \delta 153.7,152.7,149.9$, 148.0, 114.9, 88.1, 83.6, 76.5, 76.3, 71.8, 62.5, 57.3, 37.9; UV $\lambda_{\max }(\mathrm{nm}): 260$; HR-ESI MS $(m / z):[\mathrm{M}+\mathrm{H}]^{+}$ calculated for $\mathrm{C}_{13} \mathrm{H}_{16} \mathrm{~N}_{5} \mathrm{O}_{4}, 306.1196$; found 306.1196 .

\subsubsection{8-Propynylamino-2'-deoxyadenosine (3)}

To a stirred solution of 8-bromoadenosine $13(0.250 \mathrm{~g}, 0.76 \mathrm{mmol})$ in absolute ethanol $(20 \mathrm{~mL})$ was added calcium carbonate $(0.151 \mathrm{~g}, 1.52 \mathrm{mmol})$ and propargylamine $(0.970 \mathrm{~mL}, 15.15 \mathrm{mmol})$ at $\mathrm{rt}$ under $\mathrm{N}_{2} \mathrm{~atm}$. The reaction mixture was slowly heated at $70-80{ }^{\circ} \mathrm{C}$ for $14 \mathrm{~h}$, then the reaction mixture was filtered to remove the calcium salts, and the filtrate was concentrated by rotary evaporation. The residue was purified by column chromatography on silica gel (MeOH:DCM $=1: 9)$ affording $3(0.170 \mathrm{~g}$, 72.6\%) as a white solid. ${ }^{1} \mathrm{H}-\mathrm{NMR}(300 \mathrm{MHz}, \mathrm{MeOD}) \delta 8.01(\mathrm{~s}, 1 \mathrm{H}, \mathrm{H} 2), 6.46(\mathrm{dd}, J=9.3,5.8 \mathrm{~Hz}, 1 \mathrm{H}$, $\left.\mathrm{H} 1^{\prime}\right), 4.59\left(\mathrm{dt}, J=6.1,1.9 \mathrm{~Hz}, 1 \mathrm{H}, \mathrm{H}^{\prime}\right), 4.17\left(\mathrm{dd}, J=2.5,1.5 \mathrm{~Hz}, 2 \mathrm{H}, \mathrm{NHCH}_{2}\right), 4.07(\mathrm{q}, J=2.1 \mathrm{~Hz}, 1 \mathrm{H}$, H4'), 3.95-3.78 (m, 2H, H5'), $2.74\left(\mathrm{ddd}, J=13.4,9.3,6.1 \mathrm{~Hz}, 1 \mathrm{H}, \mathrm{H2}{ }^{\prime} \mathrm{a}\right), 2.63(\mathrm{t}, J=2.4 \mathrm{~Hz}, 1 \mathrm{H}, \mathrm{CH}), 2.19$ $\left(\mathrm{ddd}, J=13.4,5.9,1.7 \mathrm{~Hz}, 1 \mathrm{H}, \mathrm{H2}{ }^{\prime} \mathrm{b}\right) ;{ }^{13} \mathrm{C}-\mathrm{NMR}(75 \mathrm{MHz}, \mathrm{MeOD}) \delta 151.9,150.8,148.8,148.5,116.1,87.5$, 83.6, 79.5, 71.6, 70.6, 61.4, 37.9, 30.9; UV $\lambda_{\max }(\mathrm{nm}): 276$; HR-ESI MS $(m / z):[\mathrm{M}+\mathrm{H}]^{+}$calculated for $\mathrm{C}_{13} \mathrm{H}_{17} \mathrm{~N}_{6} \mathrm{O}_{3}, 305.1356$; found 305.1361.

\subsubsection{8-Bromo-2'-deoxyguanosine (17)}

To a stirred solution of $\mathbf{1 6}(3.0 \mathrm{~g}, 11.23 \mathrm{mmol})$ in $\mathrm{MeCN}(120 \mathrm{~mL})$ and $\mathrm{H}_{2} \mathrm{O}(30 \mathrm{~mL})$ was added $\mathrm{N}$-bromosuccinimide (NBS; $3.0 \mathrm{~g}, 16.85 \mathrm{mmol}$ ) in three portions. The suspension was stirred for $45 \mathrm{~min}$ 
at rt, and subsequently evaporated to dryness. The residual solid was filtered. The solid was washed with cold acetone $(100 \mathrm{~mL})$ and dried in vacuo to give the title compound $\mathbf{1 7}(3.53 \mathrm{~g}, 91 \%)$ as an orange solid. ${ }^{1} \mathrm{H}-\mathrm{NMR}\left(300 \mathrm{MHz}, \mathrm{DMSO}-\mathrm{d}_{6}\right) \delta 10.80(\mathrm{~s}, 1 \mathrm{H}, \mathrm{NH}), 6.16\left(\mathrm{t}, J=7.3 \mathrm{~Hz}, 1 \mathrm{H}, \mathrm{H1}{ }^{\prime}\right), 4.40(\mathrm{dt}, J=6.1$, $\left.3.0 \mathrm{~Hz}, 1 \mathrm{H}, \mathrm{H3}^{\prime}\right), 3.81\left(\mathrm{td}, J=5.5,2.9 \mathrm{~Hz}, 1 \mathrm{H}, \mathrm{H} 4^{\prime}\right), 3.63\left(\mathrm{dd}, J=11.7,5.4 \mathrm{~Hz}, 1 \mathrm{H}, \mathrm{H}^{\prime} \mathrm{a}\right), 3.50(\mathrm{dd}$, $\left.J=11.6,5.9 \mathrm{~Hz}, 1 \mathrm{H}, \mathrm{H}^{\prime} \mathrm{b}\right), 3.17\left(\mathrm{dt}, J=13.8,7.1 \mathrm{~Hz}, 1 \mathrm{H}, \mathrm{H} 2^{\prime} \mathrm{a}\right), 2.11$ (ddd, $\left.J=13.7,7.0,2.8 \mathrm{~Hz}, 1 \mathrm{H}, \mathrm{H} 2^{\prime} \mathrm{b}\right)$; ${ }^{13} \mathrm{C}-\mathrm{NMR}$ (75 MHz, DMSO) $\delta$ 155.6, 153.5, 152.1, 120.7, 117.6, 88.0, 85.2, 71.2, 62.2, 36.6; HR-ESI MS $(m / z):[\mathrm{M}+\mathrm{H}]^{+}$calculated for $\mathrm{C}_{10} \mathrm{H}_{13} \mathrm{BrN}_{5} \mathrm{O}_{4}, 346.0145$; found, 346.0145 [24].

\subsubsection{8-Bromo-3', 5'-O-bis(tert-butyldimethylsilyl)-2'-deoxyguanosine (18)}

To a stirred solution of $17(3 \mathrm{~g}, 8.67 \mathrm{mmol})$ in dry DMF $(60 \mathrm{~mL})$ was added imidazole $(3.54 \mathrm{~g}$, $52.0 \mathrm{mmol}$ ) and tert butyl(chloro)dimethylsilane $\left(3.92 \mathrm{~g}, 26.0 \mathrm{mmol}\right.$ ) at rt under $\mathrm{N}_{2} \mathrm{~atm}$. After $15 \mathrm{~h}$, solvents were removed in vacuo. The reaction mixture was diluted with EtOAc $(60 \mathrm{~mL})$, quenched with sat aq. $\mathrm{NaHCO}_{3}$ solution $(30 \mathrm{~mL})$, and diluted with $\mathrm{H}_{2} \mathrm{O}(30 \mathrm{~mL})$. The aqueous phase was extracted with EtOAc $(3 \times 60 \mathrm{~mL})$, and the combined organic phases were dried $\left(\mathrm{Na}_{2} \mathrm{SO}_{4}\right)$, filtered, and the solvent was removed in vacuo. The residue was purified by column chromatography on silica gel (MeOH:DCM = 6:94) to give the title compound $18(4.3 \mathrm{~g}, 87 \%)$ as a pale yellow solid; ${ }^{1} \mathrm{H}-\mathrm{NMR}$ $\left(300 \mathrm{MHz}, \mathrm{CDCl}_{3}\right) \delta 11.90$ (brs, 1H, NH), 6.48 (brs, 2H, NH$)_{2}, 6.24\left(\mathrm{t}, J=6.9 \mathrm{~Hz}, 1 \mathrm{H}, \mathrm{H1} 1^{\prime}\right), 4.75(\mathrm{dt}$, $\left.J=6.5,3.6 \mathrm{~Hz}, 1 \mathrm{H}, \mathrm{H}^{\prime}\right), 3.90\left(\mathrm{~m}, 2 \mathrm{H}, \mathrm{H} 4^{\prime}, \mathrm{H}^{\prime} \mathrm{a}\right), 3.73\left(\mathrm{dd}, J=10.2,5.1 \mathrm{~Hz}, 1 \mathrm{H}, \mathrm{H} 5^{\prime} \mathrm{b}\right), 3.50(\mathrm{dt}, J=12.8$, $\left.6.4 \mathrm{~Hz}, 1 \mathrm{H}, \mathrm{H} 2^{\prime} \mathrm{a}\right), 2.18$ (ddd, $J=12.8,6.7,3.9 \mathrm{~Hz}, 1 \mathrm{H}, \mathrm{H} 2$ 'b). $0.96\left(\mathrm{~s}, 9 \mathrm{H}, \mathrm{Si}\left(\mathrm{CH}_{3}\right)_{3}\right), 0.88\left(\mathrm{~s}, 9 \mathrm{H}, \mathrm{Si}\left(\mathrm{CH}_{3}\right)_{3}\right)$, $0.16\left(\mathrm{~s}, 6 \mathrm{H}, \mathrm{Si}\left(\mathrm{CH}_{3}\right)_{2}\right), 0.05$ (s, 3H, Si $\left.\left(\mathrm{CH}_{3}\right)\right), 0.03\left(\mathrm{~s}, 3 \mathrm{H}, \mathrm{Si}\left(\mathrm{CH}_{3}\right) ;{ }^{13} \mathrm{C}-\mathrm{NMR}\left(75 \mathrm{MHz}, \mathrm{CDCl}_{3}\right) \delta 157.6\right.$, 152.8, 152.3, 122.0, 117.6, 87.3, 85.5, 72.1, 62.5, 36.3, 25.6, 25.5, 18.0, 17.7, -4.9, -4.9, -5.7, -5.7; HR-ESI MS $(m / z):[\mathrm{M}+\mathrm{H}]^{+}$calculated for $\mathrm{C}_{22} \mathrm{H}_{41} \mathrm{BrN}_{5} \mathrm{O}_{4} \mathrm{Si}_{2}, 574.1875$; found 574.1888 [16].

\subsubsection{8-Bromo-3', $5^{\prime}$-O-bis(tert-butyldimethylsilyl)-6-O-(trimethylsilylethyl)-2'-deoxyguanosine (19)}

Compound 18 (4.00 g, $6.96 \mathrm{mmol})$, triphenylphosphine (2.74 g, $10.45 \mathrm{mmol})$ and 2-(trimethylsilyl)ethanol $(1.51 \mathrm{~mL}, 10.45 \mathrm{mmol})$ were mixed in anhydrous dioxane $(80 \mathrm{~mL})$. The mixture was stirred at $\mathrm{rt}$ for $10 \mathrm{~min}$, and then cooled down to $0{ }^{\circ} \mathrm{C}$. Diisopropyl azodicarboxylate (DIAD) $(2.05 \mathrm{~mL}, 10.45 \mathrm{mmol})$ was added and the mixture was heated at $40{ }^{\circ} \mathrm{C}$ for $24 \mathrm{~h}$. The resulting mixture was concentrated in vacuo, and the residue was diluted with EtOAc (100 mL) and water $(100 \mathrm{~mL})$. The layers were separated and the aqueous layer was extracted with EtOAc $(3 \times 100 \mathrm{~mL})$. The combined organic layers were washed with brine $(50 \mathrm{~mL})$, dried $\left(\mathrm{Na}_{2} \mathrm{SO}_{4}\right)$ and the solvent was removed in vacuo. The residue was purified by column chromatography on silica gel (EtOAc:hexane $=1: 9)$ to give the title compound 19 (3.05 g, 65\%) as colorless oil; ${ }^{1} \mathrm{H}-\mathrm{NMR}\left(300 \mathrm{MHz}, \mathrm{CDCl}_{3}\right) \delta 6.29(\mathrm{t}, J=6.8 \mathrm{~Hz}, 1 \mathrm{H}$, $\mathrm{H1}^{\prime}$ ), 4.83-4.77 (m, 1H, H3') 4.75 (brs, 2H, NH${ }_{2}$ ), 4.63-4.44 (m, 2H, OCH $), 3.98-3.83$ (m, 2H, H4', H5'a), 3.71 (dd, $\left.J=10.2,4.3 \mathrm{~Hz}, 1 \mathrm{H}, \mathrm{H}^{\prime}{ }^{\prime} \mathrm{b}\right), 3.56$ (dt, $\left.J=13.0,6.4 \mathrm{~Hz}, 1 \mathrm{H}, \mathrm{H} 2^{\prime} \mathrm{a}\right), 2.17$ (ddd, J = 13.0, 6.8, $\left.4.0 \mathrm{~Hz}, 1 \mathrm{H}, \mathrm{H}_{2}^{\prime} \mathrm{b}\right), 1.26-1.18\left(\mathrm{~m}, 2 \mathrm{H}, \mathrm{CH}_{2} \mathrm{Si}\right), 0.95\left(\mathrm{~s}, 9 \mathrm{H}, \mathrm{SiC}\left(\mathrm{CH}_{3}\right)_{3}\right), 0.86\left(\mathrm{~s}, 9 \mathrm{H}, \mathrm{SiC}\left(\mathrm{CH}_{3}\right)_{3}\right), 0.15(\mathrm{~s}$, $\left.6 \mathrm{H}, \mathrm{Si}\left(\mathrm{CH}_{3}\right)_{2}\right), 0.09$ (s, 9H, $\left.\mathrm{SiC}\left(\mathrm{CH}_{3}\right)_{3}\right), 0.03\left(\mathrm{~s}, 3 \mathrm{H}, \mathrm{SiCH}_{3}\right),-0.01\left(\mathrm{~s}, 3 \mathrm{H}, \mathrm{SiCH}_{3}\right) ;{ }^{13} \mathrm{C}-\mathrm{NMR}(75 \mathrm{MHz}$, $\left.\mathrm{CDCl}_{3}\right) \delta 159.9,158.3,153.9,125.3,116.3,87.1,85.4,72.1,64.7,62.4,36.1,25.6,25.5,18.0,17.7,17.2,-1.8$, $-4.9,-5.0,-5.7,-5.8$; HR-ESI MS $(m / z):[\mathrm{M}+\mathrm{H}]^{+}$calculated for $\mathrm{C}_{27} \mathrm{H}_{53} \mathrm{BrN}_{5} \mathrm{O}_{4} \mathrm{Si}_{3}, 674.2583$; found 674.2590 [16].

3.1.8. 8-Bromo-3', $5^{\prime}$-O-bis(tert-butyldimethylsilyl)-2- $\mathrm{N}$-isobutyryl-6-O-(trimethylsilylethyl)-2' deoxyguanosine (20)

To a stirred solution of $19(0.900 \mathrm{~g}, 1.2 \mathrm{mmol})$ in dry pyridine $(10 \mathrm{~mL})$ was added isobutyrylchloride $(0.25 \mathrm{~mL}, 2.4 \mathrm{mmol})$ at $0{ }^{\circ} \mathrm{C}$ under Ar gas and the mixture was stirred for $3 \mathrm{~h}$ at $\mathrm{rt}$. The reaction mixture was quenched with saturated aqueous $\mathrm{NaHCO}_{3}(25 \mathrm{~mL})$ and extracted with $\mathrm{DCM}(3 \times 50 \mathrm{~mL})$. The combined organic layers were washed with brine $(50 \mathrm{~mL})$, dried $\left(\mathrm{Na}_{2} \mathrm{SO}_{4}\right)$, filtered, and the solvent was removed in vacuo. The residue was purified by flash column chromatography on silica gel (EtOAc:hexane = 1:9) to give the title compound $20(0.845 \mathrm{~g}, 85 \%)$ as colorless oil. ${ }^{1} \mathrm{H}-\mathrm{NMR}(300 \mathrm{MHz}$, $\left.\mathrm{CDCl}_{3}\right) \delta 7.71(\mathrm{~s}, 1 \mathrm{H}, \mathrm{NH}), 6.36\left(\mathrm{t}, J=7.0 \mathrm{~Hz}, 1 \mathrm{H}, \mathrm{H1} 1^{\prime}\right), 4.85\left(\mathrm{dt}, J=6.1,3.2 \mathrm{~Hz}, 1 \mathrm{H}, \mathrm{H3}^{\prime}\right), 4.66-4.50(\mathrm{~m}$, 
$\left.2 \mathrm{H}, \mathrm{OCH}_{2}\right), 4.02-3.84\left(\mathrm{~m}, 2 \mathrm{H}, \mathrm{H} 4^{\prime}, \mathrm{H}^{\prime} \mathrm{a}\right), 3.74\left(\mathrm{dd}, J=10.6,5.2 \mathrm{~Hz}, 1 \mathrm{H}, \mathrm{H} 5^{\prime} \mathrm{b}\right), 3.59(\mathrm{dt}, J=13.3,6.5 \mathrm{~Hz}$, $\left.1 \mathrm{H}, \mathrm{H} 2^{\prime} \mathrm{a}\right), 3.10$ (brs, $\left.1 \mathrm{H}, \mathrm{COCH}\right), 2.21$ (ddd, $\left.J=13.1,6.6,3.5 \mathrm{~Hz}, 1 \mathrm{H}, \mathrm{H} 2^{\prime} \mathrm{b}\right), 1.34-1.20\left(\mathrm{~m}, 8 \mathrm{H}, \mathrm{C}\left(\mathrm{CH}_{3}\right) 2\right.$, $\left.\mathrm{CH}_{2} \mathrm{Si}\right), 0.94\left(\mathrm{~s}, 9 \mathrm{H}, \mathrm{SiC}\left(\mathrm{CH}_{3}\right)_{3}\right), 0.86\left(\mathrm{~s}, 9 \mathrm{H}, \mathrm{SiC}\left(\mathrm{CH}_{3}\right)_{3}\right), 0.17\left(\mathrm{~s}, 3 \mathrm{H}, \mathrm{SiCH}_{3}\right), 0.15\left(\mathrm{~s}, 3 \mathrm{H}, \mathrm{SiCH}_{3}\right), 0.11$ $\left(\mathrm{s}, 9 \mathrm{H}, \mathrm{SiC}\left(\mathrm{CH}_{3}\right)_{3}\right), 0.02\left(\mathrm{~s}, 3 \mathrm{H}, \mathrm{SiCH}_{3}\right), 0.01\left(\mathrm{~s}, 3 \mathrm{H}, \mathrm{SiCH}_{3}\right) ;{ }^{13} \mathrm{C}-\mathrm{NMR}\left(75 \mathrm{MHz}, \mathrm{CDCl}_{3}\right) \delta$ 175.1, 159.6, 153.0, 151.0, 128.2, 118.7, 87.8, 85.8, 72.2, 65.6, 62.9, 36.5, 35.2, 25.6, 25.5, 19.0, 18.9, 18.0, 17.6, 17.1, -1.8, -5.0, -5.7. HR-ESI MS $(m / z)$ : $[\mathrm{M}+\mathrm{H}]^{+}$calculated for $\mathrm{C}_{31} \mathrm{H}_{59} \mathrm{Br}_{1} \mathrm{~N}_{5} \mathrm{O}_{5} \mathrm{Si}_{3}, 744.3002$; found 744.3018.

3.1.9. $3^{\prime}, 5^{\prime}$-O-Bis(tert-butyldimethylsilyl)-2- $\mathrm{N}$-isobutyryl-8-propynylamino-6-O(trimethyl-silylethyl)-2'-deoxyguanosine (21)

To a stirred suspension of $20(0.400 \mathrm{~g}, 0.54 \mathrm{mmol})$ in anhydrous, degassed 1.4 dioxane $(15 \mathrm{~mL})$ was added propargylamine $(0.051 \mathrm{~mL}, 0.536 \mathrm{mmol}), \mathrm{Pd}_{2}(\mathrm{dba})_{3}(50 \mathrm{mg}, 0.536 \mathrm{mmol}), \operatorname{BINAP}(100 \mathrm{mg}$, $0.536 \mathrm{mmol})$ and cesium carbonate $(0.262 \mathrm{~g}, 0.804 \mathrm{mmol})$ at $\mathrm{rt}$ under $\mathrm{N}_{2} \mathrm{~atm}$. The reaction was slowly heated at $100{ }^{\circ} \mathrm{C}$ for $48 \mathrm{~h}$, then cooled to rt and quenched with saturated aq. $\mathrm{NaHCO}_{3}(15 \mathrm{~mL})$. The aqueous phase was extracted with EtOAc $(3 \times 30 \mathrm{~mL})$, and the combined organic phases were dried $\left(\mathrm{Na}_{2} \mathrm{SO}_{4}\right)$, filtered, and the solvent was removed in vacuo. The residue was purified by column chromatography on silica gel (EtOAc:hexane $=15: 85)$ to give the title compound $\mathbf{2 1}(0.235 \mathrm{~g}, 61 \%)$ as a colorless oil. ${ }^{1} \mathrm{H}-\mathrm{NMR}\left(300 \mathrm{MHz}, \mathrm{CDCl}_{3}\right) \delta 7.70(\mathrm{~s}, 1 \mathrm{H}, \mathrm{NH}), 6.35\left(\mathrm{dd}, J=8.3,5.9 \mathrm{~Hz}, 1 \mathrm{H}, \mathrm{H1} 1^{\prime}\right), 5.82$ $(\mathrm{t}, J=5.9 \mathrm{~Hz}, 1 \mathrm{H}, \mathrm{NH}), 4.77-4.44\left(\mathrm{~m}, 3 \mathrm{H}, \mathrm{H}^{\prime}, \mathrm{OCH}_{2}\right), 4.42-4.19\left(\mathrm{~m}, 2 \mathrm{H}, \mathrm{NHCH}_{2}\right), 4.12-3.73(\mathrm{~m}, 3 \mathrm{H}$, $\left.\mathrm{H} 4^{\prime}, \mathrm{H}^{\prime}\right), 3.51$ (brs, $\left.1 \mathrm{H}, \mathrm{COCH}\right), 2.64\left(\mathrm{dt}, J=14.1,7.2 \mathrm{~Hz}, 1 \mathrm{H}, \mathrm{H2}{ }^{\prime} \mathrm{a}\right), 2.36-2.06\left(\mathrm{~m}, 2 \mathrm{H}, \mathrm{CH}, \mathrm{H} 2^{\prime} \mathrm{b}\right)$, 1.56-1.15 (m, 8H, HC(CH $\left.)_{2}, \mathrm{OCH}_{2} \mathrm{Si}\right), 0.93\left(\mathrm{~s}, 18 \mathrm{H}, 2 \times \mathrm{SiC}\left(\mathrm{CH}_{3}\right)_{3}\right), 0.41-0.00\left(\mathrm{~m}, 21 \mathrm{H}, \mathrm{SiC}\left(\mathrm{CH}_{3}\right)_{3}, 2 \times\right.$ $\left.\mathrm{Si}\left(\mathrm{CH}_{3}\right)_{2}\right) ;{ }^{13} \mathrm{C}-\mathrm{NMR}\left(75 \mathrm{MHz}, \mathrm{CDCl}_{3}\right) \delta 176.9,157.2,152.7,151.5,148.8,115.2,86.9,83.4,80.3,71.4,71.0$, $64.8,62.4,38.9,32.2,25.7,25.4,18.9,18.3,17.6,17.5,-1.8,-4.9,-5.1,-5.5,-5.7$; HR-ESI MS $(\mathrm{m} / \mathrm{z})$ : $[\mathrm{M}+\mathrm{H}]^{+}$calculated for $\mathrm{C}_{34} \mathrm{H}_{63} \mathrm{~N}_{6} \mathrm{O}_{5} \mathrm{Si}_{3}, 719.4162$; found 719.4179 .

\subsubsection{8-Propynylamino-2'-deoxyguanosine (9)}

To a stirred solution of 21 ( $0.230 \mathrm{~g}, 0.32 \mathrm{mmol})$ in THF $(10 \mathrm{~mL})$ was added TBAF ( $1 \mathrm{M}$ in THF) $(1.6 \mathrm{~mL}, 1.6 \mathrm{mmol})$ at $\mathrm{rt}$ under $\mathrm{N}_{2}$ atm. After $4 \mathrm{~h}$ the solvent was removed under reduced pressure and the crude mixture was purified by flash chromatography on silica, eluting with $20 \% \mathrm{MeOH}$ in DCM to afford the intermediate. Without further purification, the crude mixture was dissolved in a glass sealed tube was added $7 \mathrm{~N} \mathrm{NH}_{3}$ in $\mathrm{MeOH}(15 \mathrm{~mL})$ at rt. The reaction was slowly heated to $60^{\circ} \mathrm{C}$ for $14 \mathrm{~h}$, then cooled to rt, concentrated in vacuo and purified by flash column chromatography to give compound 9 along with TBAF impurities. Then to a stirred solution of the crude mixture in water $(10 \mathrm{~mL})$ was added $\mathrm{NH}_{4} \mathrm{PF}_{6}(150 \mathrm{mg})$ at $\mathrm{rt}$ for $30 \mathrm{~min}$. The mixture was washed with DCM $(3 \times 10 \mathrm{~mL})$ and water was removed in vacuo. The residue was purified by column chromatography on silica gel ( $\mathrm{MeOH}: \mathrm{DCM}=1: 3$ containing $1 \%$ aq. $\left.\mathrm{NH}_{3}\right)$ and afforded the alkyn $9(66 \mathrm{mg}, 65 \%$ overall for both steps) as a colorless oil. ${ }^{1} \mathrm{H}-\mathrm{NMR}(300 \mathrm{MHz}, \mathrm{MeOD}) \delta 6.34\left(\mathrm{dd}, J=9.1,6.0 \mathrm{~Hz}, 1 \mathrm{H}, \mathrm{H1} 1^{\prime}\right), 4.57(\mathrm{dt}, J=6.5$, $\left.2.2 \mathrm{~Hz}, 1 \mathrm{H}, \mathrm{H3}^{\prime}\right), 4.18-4.04\left(\mathrm{~m}, 2 \mathrm{H}, \mathrm{NHCH}_{2}\right), 4.00\left(\mathrm{q}, J=2.5 \mathrm{~Hz}, 1 \mathrm{H}, \mathrm{H} 4^{\prime}\right), 3.95-3.69$ (m, 2H, H5' a), 2.73 (ddd, $\left.J=13.1,9.2,6.4 \mathrm{~Hz}, 1 \mathrm{H}, \mathrm{H2}{ }^{\prime} \mathrm{a}\right), 2.55$ (t, $\left.J=2.5 \mathrm{~Hz}, 1 \mathrm{H}, \mathrm{CH}\right), 2.12$ (ddd, $J=13.4,5.9,1.9 \mathrm{~Hz}, 1 \mathrm{H}$, H2'b) ${ }^{13}{ }^{C}$-NMR (75 MHz, MeOD) $\delta$ 156.4, 152.2, 150.7, 148.8, 111.9, 87.1, 83.1, 79.9, 71.4, 70.3, 61.1, 37.6, 31.1; UV $\lambda_{\max }(\mathrm{nm}): 260$ (br); HR-ESI MS ( $\left.m / z\right)$ : $[\mathrm{M}+\mathrm{H}]^{+}$calculated for $\mathrm{C}_{13} \mathrm{H}_{17} \mathrm{~N}_{6} \mathrm{O}_{4}, 321.1305$; found 321.1303 .

\subsubsection{3', 5'-O-Bis(tert-butyldimethylsilyl)-2'-deoxyguanosine (22)}

To a stirred solution of 2'-deoxyguanosine $16(1.2 \mathrm{~g}, 4.49 \mathrm{mmol})$ in dry DMF $(60 \mathrm{~mL})$ was added imidazole $(1.83 \mathrm{~g}, 26.96 \mathrm{mmol})$ and TBDMSCl $(2.032 \mathrm{~g}, 13.48 \mathrm{mmol})$ at $\mathrm{rt}$ under $\mathrm{N}_{2} \mathrm{~atm}$. After $24 \mathrm{~h}$, DMF was evaporated in vacuo and the residue was partitioned between water $(60 \mathrm{~mL})$ and EtOAc $(60 \mathrm{~mL})$ were added $(60 \mathrm{~mL})$. The aqueous phase was extracted with EtOAc $(3 \times 60 \mathrm{~mL})$, and the combined organic phases were dried $\left(\mathrm{Na}_{2} \mathrm{SO}_{4}\right)$, filtered, and the solvent was removed in vacuo. The residue was purified by column chromatography on silica gel (MeOH:DCM = 5:95) affording $22(1.86 \mathrm{~g}$, $84 \%$ ) as a white solid. ${ }^{1} \mathrm{H}-\mathrm{NMR}\left(300 \mathrm{MHz}, \mathrm{DMSO}-d_{6}\right) \delta 10.62(\mathrm{~s}, 1 \mathrm{H}, \mathrm{NH}), 7.89(\mathrm{~s}, 1 \mathrm{H}, \mathrm{H} 8), 6.48$ (s, 
$\left.2 \mathrm{H}, \mathrm{NH}_{2}\right), 6.11\left(\mathrm{dd}, J=7.7,6.0 \mathrm{~Hz}, 1 \mathrm{H}, \mathrm{H} 1^{\prime}\right), 4.52-4.44\left(\mathrm{~m}, 1 \mathrm{H}, \mathrm{H}^{\prime}\right), 3.81\left(\mathrm{dd}, J=5.5,2.8 \mathrm{~Hz}, 1 \mathrm{H}, \mathrm{H} 4^{\prime}\right)$, 3.75-3.61 (m, 2H, H5'), 2.72-2.58 (m, 1H, H2' a), $2.24\left(\mathrm{ddd}, J=13.2,6.0,3.2 \mathrm{~Hz}, 1 \mathrm{H}, \mathrm{H} 2^{\prime} \mathrm{b}\right), 0.89$ (d, $\left.J=5.1 \mathrm{~Hz}, 18 \mathrm{H}, 2 \times \mathrm{SiC}\left(\mathrm{CH}_{3}\right)_{3}\right), 0.11\left(\mathrm{~s}, 6 \mathrm{H}, \mathrm{SiC}\left(\mathrm{CH}_{3}\right)_{2}\right), 0.05\left(\mathrm{~d}, J=1.5 \mathrm{~Hz}, 6 \mathrm{H}, \mathrm{SiC}\left(\mathrm{CH}_{3}\right)_{2}\right) ;{ }^{13} \mathrm{C}-\mathrm{NMR}$ (75 MHz, DMSO) $\delta 156.8,153.9,151.1,135.0,116.8,87.1,82.3,72.3,62.9,25.9,25.8,18.1,17.8,-4.6,-4.8$, $-5.3,-5.4$; HR-ESI MS $(m / z)$ : [M + H] ${ }^{+}$calculated for $\mathrm{C}_{22} \mathrm{H}_{42} \mathrm{~N}_{5} \mathrm{O}_{4} \mathrm{Si}_{2}, 496.2766$; found 496.2769 [25].

\subsubsection{2. $3^{\prime}, 5^{\prime}$-O-Bis(tert-butyldimethylsilyl)-6-O-propynyl-2'-deoxyguanosine (23)}

To a stirred solution of $22(0.500 \mathrm{~g}, 1.01 \mathrm{mmol})$ in dry 1,4 dioxane $(40 \mathrm{~mL})$ was added triphenyl phosphine $(0.317 \mathrm{~g}, 1.21 \mathrm{mmol})$ at $\mathrm{rt}$ under $\mathrm{N}_{2} \mathrm{~atm}$. The reaction mixture was slowly heated at $60{ }^{\circ} \mathrm{C}$ for $1 \mathrm{~h}$, propargylalcohol $(0.087 \mathrm{~mL}, 1.51 \mathrm{mmol})$ was added and after stirring for $30 \mathrm{~min}$, DIAD $(0.300 \mathrm{~mL}$, $1.51 \mathrm{mmol}$ ) was added and the mixture was further stirred overnight at $60{ }^{\circ} \mathrm{C}$. The crude reaction mixture was concentrated in vacuo, and the mixture was purified by silica gel column chromatography (hexane:EtOAc $=6: 4)$ to give $23(0.266 \mathrm{mg}, 50 \%)$ as a white solid: ${ }^{1} \mathrm{H}-\mathrm{NMR}\left(300 \mathrm{MHz}, \mathrm{CDCl}_{3}\right) \delta 7.93(\mathrm{~s}$, $1 \mathrm{H}, \mathrm{H} 8), 6.31\left(\mathrm{t}, J=6.5 \mathrm{~Hz}, 1 \mathrm{H}, \mathrm{H1} 1^{\prime}\right), 5.10\left(\mathrm{dd}, J=2.4,0.8 \mathrm{~Hz}, 2 \mathrm{H}, \mathrm{OCH}_{2}\right), 5.07\left(\mathrm{brs}, 2 \mathrm{H}, \mathrm{NH}_{2}\right), 4.58(\mathrm{dt}$, $\left.J=5.6,3.5 \mathrm{~Hz}, 1 \mathrm{H}, \mathrm{H} 3^{\prime}\right), 3.97\left(\mathrm{q}, J=3.5 \mathrm{~Hz}, 1 \mathrm{H}, \mathrm{H} 4^{\prime}\right), 3.78\left(\mathrm{qd}, J=11.2,3.5 \mathrm{~Hz}, 2 \mathrm{H}, \mathrm{H} 5^{\prime}\right), 2.61-2.49(\mathrm{~m}$, $\left.1 \mathrm{H}, \mathrm{H} 2^{\prime} \mathrm{a}\right), 2.46(\mathrm{t}, J=2.4 \mathrm{~Hz}, 1 \mathrm{H}, \mathrm{CH}), 2.40-2.32\left(\mathrm{~m}, 1 \mathrm{H}, \mathrm{H} 2^{\prime} \mathrm{b}\right), 0.90\left(\mathrm{~s}, 18 \mathrm{H}, 2 \mathrm{xiC}\left(\mathrm{CH}_{3}\right)_{3}\right), 0.09(\mathrm{~s}, 6 \mathrm{H}$, $\left.\mathrm{SiC}\left(\mathrm{CH}_{3}\right)_{2}\right), 0.07\left(\mathrm{~s}, 6 \mathrm{H}, \mathrm{SiC}\left(\mathrm{CH}_{3}\right)_{2}\right) ;{ }^{13} \mathrm{C}-\mathrm{NMR}\left(75 \mathrm{MHz}, \mathrm{CDCl}_{3}\right) \delta 159.5,158.7,153.5,137.5,115.4,87.3$, 83.3, 78.06, 74.5, 71.5, 62.4, 53.4, 40.6, 25.6, 25.4, 18.1, 17.7, -5.0, -5.1, -5.7, -5.8; HR-ESI MS ( $m / z)$ : $[\mathrm{M}+\mathrm{H}]^{+}$calculated for $\mathrm{C}_{25} \mathrm{H}_{44} \mathrm{~N}_{5} \mathrm{O}_{4} \mathrm{Si}_{2}, 534.2926$; found 534.2930.

\subsubsection{3',5'-O-Bis(tert-butyldimethylsilyl)-6-N-propynyl-2,6-diaminopurine-2'-deoxyriboside (24)}

To a stirred solution of $22(0.300 \mathrm{~g}, 0.606 \mathrm{mmol})$ in dry DCM $(50 \mathrm{~mL})$ was added $\mathrm{Et}_{3} \mathrm{~N}(0.25 \mathrm{~mL}$, $1.82 \mathrm{mmol}), \operatorname{TIBSCl}(0.55 \mathrm{~g}, 1.82 \mathrm{mmol})$ and DMAP $(9 \mathrm{mg}, 0.08 \mathrm{mmol})$ at rt. After stirring for $48 \mathrm{~h}$, the reaction mixture was concentrated in vacuo and the residue was partitioned between EtOAc $(30 \mathrm{~mL})$ and water $(30 \mathrm{~mL})$. The aq. layer was again extracted with EtOAc $(3 \times 30 \mathrm{~mL})$. The combined organic layer was washed with water $(50 \mathrm{~mL})$ and brine $(50 \mathrm{~mL})$, dried over $\mathrm{Na}_{2} \mathrm{SO}_{4}$, filtered and evaporated under vacuum to get crude compound. The crude mixture was dissolved in a glass sealed tube $30 \mathrm{~mL}$ of EtOH and propargylamine $(0.776 \mathrm{~mL}, 12.12 \mathrm{mmol})$ and DIPEA $(0.526 \mathrm{~mL}, 3.03 \mathrm{mmol})$ were added at rt. The reaction mixture was slowly heated to $100{ }^{\circ} \mathrm{C}$ for $14 \mathrm{~h}$. The reaction was quenched by saturated aqueous $\mathrm{NaHCO}_{3}$, and $\mathrm{EtOH}$ was removed under reduced pressure. The aqueous layer was extracted with EtOAc $(3 \times 50 \mathrm{~mL})$. The organic layer was washed with water $(50 \mathrm{~mL})$ and brine $(50 \mathrm{~mL})$, dried over $\mathrm{Na}_{2} \mathrm{SO}_{4}$, and evaporated under vacuum. The residue was purified by flash silica gel chromatography (hexane:EtOAc $=6: 4)$ to give compound $24(0.178 \mathrm{~g}, 55 \%)$ as a white solid. ${ }^{1} \mathrm{H}-\mathrm{NMR}$ $\left(300 \mathrm{MHz}, \mathrm{CDCl}_{3}\right) \delta 7.80(\mathrm{~s}, 1 \mathrm{H}, \mathrm{H} 8), 6.31\left(\mathrm{t}, J=6.5 \mathrm{~Hz}, 1 \mathrm{H}, \mathrm{H} 1^{\prime}\right), 5.83(\mathrm{t}, J=5.1 \mathrm{~Hz}, 1 \mathrm{H}, \mathrm{NH}), 4.77(\mathrm{~s}, 2 \mathrm{H}$, $\left.\mathrm{NH}_{2}\right), 4.60\left(\mathrm{dt}, J=6.0,3.2 \mathrm{~Hz}, 1 \mathrm{H}, \mathrm{H}^{\prime}\right), 4.40\left(\mathrm{~d}, J=2.7 \mathrm{~Hz}, 2 \mathrm{H}, \mathrm{NHCH}_{2}\right), 3.98(\mathrm{dd}, J=6.6,3.3 \mathrm{~Hz}, 1 \mathrm{H}$, $\left.\mathrm{H} 4^{\prime}\right), 3.80\left(\mathrm{qd}, J=11.2,3.9 \mathrm{~Hz}, 2 \mathrm{H}, \mathrm{H}^{\prime}\right), 2.60\left(\mathrm{dt}^{\prime} J=12.9,6.4 \mathrm{~Hz}, 1 \mathrm{H}, \mathrm{H} 2^{\prime} \mathrm{a}\right), 2.42-2.30\left(\mathrm{~m}, 1 \mathrm{H}, \mathrm{H} 2^{\prime} \mathrm{b}\right)$, $2.25(\mathrm{t}, J=2.4 \mathrm{~Hz}, 1 \mathrm{H}, \mathrm{CH}), 0.93\left(\mathrm{~s}, 18 \mathrm{H}, 2 \mathrm{xiC}\left(\mathrm{CH}_{3}\right)_{3}\right), 0.11\left(\mathrm{~s}, 6 \mathrm{H}, \mathrm{SiC}\left(\mathrm{CH}_{3}\right)_{2}\right), 0.10\left(\mathrm{~s}, 6 \mathrm{H}, \mathrm{SiC}\left(\mathrm{CH}_{3}\right)_{2}\right)$; ${ }^{13} \mathrm{C}-\mathrm{NMR}\left(75 \mathrm{MHz}, \mathrm{CDCl}_{3}\right) \delta$ 159.4, 154.0, 150.9, 135.6, 114.7, 87.3, 83.2, 80.0, 71.7, 71.0, 62.5, 40.4, 29.9, 25.6, 25.4, 18.1, 17.7, $-4.9,-5.1,-5.7,-5.8$; HR-ESI MS $(m / z)$ : $[\mathrm{M}+\mathrm{H}]^{+}$calculated for $\mathrm{C}_{25} \mathrm{H}_{45} \mathrm{~N}_{6} \mathrm{O}_{3} \mathrm{Si}_{2}$, 533.3086; found 533.3088.

\subsubsection{6-O-Propynyl-2'-deoxyguanosine (5)}

To a stirred solution of compound $23(0.240 \mathrm{~g}, 0.45 \mathrm{mmol})$ in THF $(15 \mathrm{~mL})$ was added TBAF $(1 \mathrm{M}$ in THF) $(1.80 \mathrm{~mL}, 1.80 \mathrm{mmol})$ at rt. After $2 \mathrm{~h}$, the solvent was removed in vacuo, and the residue was purified by flash column chromatography on silica gel $(\mathrm{MeOH}: \mathrm{DCM}=1: 9)$ to give the title compound 5 (116 mg, 85\%) as a white solid. ${ }^{1} \mathrm{H}-\mathrm{NMR}(300 \mathrm{MHz}, \mathrm{MeOD}) \delta 8.06(\mathrm{~s}, 1 \mathrm{H}, \mathrm{H} 8), 6.32(\mathrm{dd}, J=7.8,6.1 \mathrm{~Hz}$, $\left.1 \mathrm{H}, \mathrm{H1}^{\prime}\right), 5.13\left(\mathrm{~d}, J=2.4 \mathrm{~Hz}, 2 \mathrm{H}, \mathrm{OCH}_{2}\right), 4.58\left(\mathrm{dd}, J=5.5,2.7 \mathrm{~Hz}, 1 \mathrm{H}, \mathrm{H}^{\prime}\right), 4.06(\mathrm{dd}, J=5.6,2.9 \mathrm{~Hz}, 1 \mathrm{H}$, $\left.\mathrm{H}^{\prime}\right), 3.91-3.70\left(\mathrm{~m}, 2 \mathrm{H}, \mathrm{H}^{\prime}\right), 2.96(\mathrm{t}, J=2.4 \mathrm{~Hz}, 1 \mathrm{H}, \mathrm{CH}), 2.79\left(\mathrm{ddd}, J=13.7,7.8,6.1 \mathrm{~Hz}, 1 \mathrm{H}, \mathrm{H} 2^{\prime} \mathrm{a}\right), 2.37$ (ddd, $\left.J=13.4,6.1,2.7 \mathrm{~Hz}, 1 \mathrm{H}, \mathrm{H} 2{ }^{\prime} \mathrm{b}\right) ;{ }^{13} \mathrm{C}-\mathrm{NMR}(75 \mathrm{MHz}, \mathrm{MeOD}) \delta 159.5,159.4,152.8,138.6,114.1,87.9$, 
84.9, 77.6, 74.9, 71.4, 61.9, 53.0, 39.4; UV $\lambda_{\max }$ (nm): 210, 245 (br), 280 (br); HR-ESI MS ( $\left.m / z\right):[\mathrm{M}+\mathrm{H}]^{+}$ calculated for $\mathrm{C}_{13} \mathrm{H}_{16} \mathrm{~N}_{5} \mathrm{O}_{4}, 306.1196$; found 306.1197 [12].

\subsubsection{6-N-Propynyl-2,6-diaminopurine-2'-deoxyriboside (6)}

To a stirred solution of $24(0.160 \mathrm{~g}, 0.300 \mathrm{mmol})$ in $\mathrm{MeOH}(20 \mathrm{~mL})$ was added $\mathrm{NH}_{4} \mathrm{~F}(0.110 \mathrm{~g}$, $3 \mathrm{mmol}$ ) at rt. The reaction mixture was slowly heated to $60-70{ }^{\circ} \mathrm{C}$ for $24 \mathrm{~h}$. The solvent was removed in vacuo, and the residue was purified by flash column chromatography on silica gel (MeOH:DCM = 1:9) to give compound 6 (74 mg, 81\%) as a white solid. ${ }^{1} \mathrm{H}-\mathrm{NMR}(300 \mathrm{MHz}, \mathrm{MeOD}) \delta 7.90(\mathrm{~s}, 1 \mathrm{H}, \mathrm{H} 8), 6.28$ $\left(\mathrm{dd}, J=8.4,5.9 \mathrm{~Hz}, 1 \mathrm{H}, \mathrm{H1}^{\prime}\right), 4.57\left(\mathrm{dt}, J=4.1,1.8 \mathrm{~Hz}, 1 \mathrm{H}, \mathrm{H}^{\prime}\right), 4.34\left(\mathrm{~s}, 2 \mathrm{H}, \mathrm{NHCH}_{2}\right), 4.07(\mathrm{dd}, J=4.8$, $\left.2.6 \mathrm{~Hz}, 1 \mathrm{H}, \mathrm{H}^{\prime}{ }^{\prime}\right), 3.81\left(\mathrm{ddd}, J=35.9,12.3,2.8 \mathrm{~Hz}, 2 \mathrm{H}, \mathrm{H}^{\prime}\right), 2.81\left(\mathrm{ddd}, J=14.0,8.5,5.9 \mathrm{~Hz}, 1 \mathrm{H}, \mathrm{H} 2^{\prime} \mathrm{a}\right)$, $2.61(\mathrm{t}, J=2.5 \mathrm{~Hz}, 1 \mathrm{H}, \mathrm{CH}), 2.33\left(\mathrm{ddd}, J=13.4,5.9,2.2 \mathrm{~Hz}, 1 \mathrm{H}, \mathrm{H2}{ }^{\prime} \mathrm{b}\right) ;{ }^{13} \mathrm{C}-\mathrm{NMR}(75 \mathrm{MHz}, \mathrm{MeOD}) \delta$ 159.7, 154.2, 149.7, 136.6, 113.8, 88.1, 85.4, 79.7, 71.7, 70.4, 62.2, 39.4, 28.9; UV $\lambda_{\max }$ (nm): 259, 280 (br); HR-ESI MS $(m / z)$ : $[\mathrm{M}+\mathrm{H}]^{+}$calculated for $\mathrm{C}_{13} \mathrm{H}_{17} \mathrm{~N}_{6} \mathrm{O}_{3}, 305.1356$; found 305.1356.

\subsubsection{3', 5'-O-Bis(tert-butyldimethylsilyl)-2'-deoxyinosine (26)}

To a stirred solution of 2'-deoxyinosine $25(2.0 \mathrm{~g}, 7.93 \mathrm{mmol})$ in dry DMF was added imidazole $(3.77 \mathrm{~g}, 55.5 \mathrm{mmol})$ and tert-butylchlorodimethysilane $(4.76 \mathrm{~g}, 31.7 \mathrm{mmol})$ at $\mathrm{rt}$ under $\mathrm{N}_{2} \mathrm{~atm}$. The resulting yellow solution was stirred at $\mathrm{rt}$ for $24 \mathrm{~h}$. Ethanol $(20 \mathrm{~mL})$ was added and the solution was stirred for an additional $15 \mathrm{~min}$ at rt. After the solvent was evaporated, the residue was dissolved in DCM $(100 \mathrm{~mL})$, washed consecutively with aq. $\mathrm{HCl}(1 \mathrm{M})$, sat. aq. $\mathrm{Na}_{2} \mathrm{CO}_{3}$ and brine and the organic phase was dried with anh. $\mathrm{Na}_{2} \mathrm{SO}_{4}$. The solvent was evaporated in vacuo to get yield $26(3.51 \mathrm{~g}, 92 \%)$ as a white solid. ${ }^{1} \mathrm{H}-\mathrm{NMR}\left(300 \mathrm{MHz}, \mathrm{CDCl}_{3}\right) \delta 8.22(\mathrm{~s}, 1 \mathrm{H}, \mathrm{H} 8), 8.18(\mathrm{~s}, 1 \mathrm{H}, \mathrm{H} 2), 6.43(\mathrm{t}, J=6.3 \mathrm{~Hz}$, $\left.1 \mathrm{H}, \mathrm{H} 1^{\prime}\right), 4.63\left(\mathrm{dt}, J=5.6,3.8 \mathrm{~Hz}, 1 \mathrm{H}, \mathrm{H} 3^{\prime}\right), 4.04\left(\mathrm{dd}, J=6.9,3.4 \mathrm{~Hz}, 1 \mathrm{H}, \mathrm{H} 4^{\prime}\right), 3.83(\mathrm{qd}, J=11.2,3.6 \mathrm{~Hz}$, $\left.2 \mathrm{H}, \mathrm{H}^{\prime}\right), 2.66-2.37\left(\mathrm{~m}, 2 \mathrm{H}, \mathrm{H} 2^{\prime} \mathrm{a}\right), 0.93\left(\mathrm{~s}, 18 \mathrm{H}, 2 \times \mathrm{SiC}\left(\mathrm{CH}_{3}\right)_{3}\right), 0.12\left(\mathrm{~s}, 6 \mathrm{H}, \mathrm{SiC}\left(\mathrm{CH}_{3}\right)_{2}\right), 0.11(\mathrm{~s}, 6 \mathrm{H}$, $\left.\mathrm{SiC}\left(\mathrm{CH}_{3}\right)_{2}\right) ;{ }^{13} \mathrm{C}-\mathrm{NMR}\left(75 \mathrm{MHz}, \mathrm{CDCl}_{3}\right) \delta$ 158.9, 148.2, 144.6, 138.2, 124.7, 87.7, 84.2, 77.1, 76.7, 76.3, 71.4, 62.3, 41.3, 25.6, 25.4, 18.1, 17.7, $-5.0,-5.1,-5.7,-5.8$; HR-ESI MS $(m / z):[\mathrm{M}+\mathrm{H}]^{+}$calculated for $\mathrm{C}_{22} \mathrm{H}_{41} \mathrm{~N}_{4} \mathrm{O}_{4} \mathrm{Si}_{2}, 481.2660$; found 481.2665 [26].

\subsubsection{6-O-Propynyl-3',5'-O-bis(tert-butyldimethylsilyl)-2'-deoxyinosine (27)}

To a solution of $3^{\prime}, 5^{\prime}$-O-bis(tert-butyldimethylsilyl)-2'-deoxyinosine (26) (700 mg, $1.46 \mathrm{mmol}$ ) in dry THF $(10 \mathrm{~mL})$ were added 2 molar equiv each of $\mathrm{BOP}$ and $\mathrm{Cs}_{2} \mathrm{CO}_{3}$ under a nitrogen atmosphere. The mixture was stirred at room temperature for $1 \mathrm{~h}$ until the complete formation of BOP adduct. The resulting mixture was evaporated under reduced pressure; again 2 molar equiv of $\mathrm{Cs}_{2} \mathrm{CO}_{3}$ and 30 molar equiv of propargyl alcohol were added and the reaction was stirred at room temperature for $5 \mathrm{~h}$. Following completion, the reaction mixture was diluted with water $(50 \mathrm{~mL})$ and extracted with EtOAc $(3 \times 20 \mathrm{~mL})$. The organic layer was dried over $\mathrm{MgSO}_{4}$ and concentrated under reduced pressure. The crude product was purified by column chromatography on silica gel using ethyl acetate and hexane to obtained the desired product $(0.681 \mathrm{mg}, 78 \%)$ as a white solid. ${ }^{1} \mathrm{H}-\mathrm{NMR}(300 \mathrm{MHz}$, $\left.\mathrm{CDCl}_{3}\right) \delta 8.55(\mathrm{~s}, 1 \mathrm{H}, \mathrm{H} 8), 8.31(\mathrm{~s}, 1 \mathrm{H}, \mathrm{H} 2), 6.55\left(\mathrm{t}, J=6.4 \mathrm{~Hz}, 1 \mathrm{H}, \mathrm{H} 1^{\prime}\right), 5.25\left(\mathrm{t}, J=2.8 \mathrm{~Hz}, 2 \mathrm{H}, \mathrm{OCH}_{2}\right)$, $4.65\left(\mathrm{~m}, 1 \mathrm{H}, \mathrm{H3}^{\prime}\right), 4.03\left(\mathrm{~m}, 1 \mathrm{H}, \mathrm{H} 4^{\prime}\right), 3.89\left(\mathrm{qd}, J=11.2,3.6 \mathrm{~Hz}, 2 \mathrm{H}, \mathrm{H} 5^{\prime}\right), 2.70-2.60\left(\mathrm{~m}, 1 \mathrm{H}, \mathrm{H} 2^{\prime} \mathrm{b}\right)$, 2.40-2.51 (m, 2H, H2' a, CH), 0.93 (s, $\left.18 \mathrm{H}, \mathrm{SiC}\left(\mathrm{CH}_{3}\right)_{3}\right), 0.12$ (s, $12 \mathrm{H}, \mathrm{Si}\left(\mathrm{CH}_{3}\right)_{2} ;{ }^{13} \mathrm{C}-\mathrm{NMR}(75 \mathrm{MHz}$, $\left.\mathrm{CDCl}_{3}\right) \delta 159.5,152,151.8,141.2,122.1,88.1,84.7,78.3,75.2,71.9,62.8,54.3,41.7,29.8,26.1,25.9,18.5$, 18.1, -4.6, -4.7, -5.3, -5.4; HR-ESI MS $(m / z):[\mathrm{M}+\mathrm{H}]^{+}$calculated for $\mathrm{C}_{25} \mathrm{H}_{43} \mathrm{~N}_{4} \mathrm{O}_{4} \mathrm{Si}_{2}, 519.2817$; found 519.2831.

\subsubsection{6-O-Propynyl-2'deoxyinosine (7)}

To a stirred solution of the propynylated dI derivative (27) $(0.600 \mathrm{~g}, 1.16 \mathrm{mmol})$ in $\mathrm{MeOH}(30 \mathrm{~mL})$ was added $\mathrm{NH}_{4} \mathrm{~F}(0.428 \mathrm{~g}, 11.6 \mathrm{mmol})$ at rt. The reaction mixture was slowly heated to $60-70{ }^{\circ} \mathrm{C}$ and stirred for $24 \mathrm{~h}$. The solvent was removed in vacuo, and the residue was purified by flash column chromatography on silica gel $(\mathrm{MeOH}: \mathrm{DCM}=1: 9)$ to give the title compound $7(0.23 \mathrm{~g}, 71 \%)$ as a white 
solid. ${ }^{1} \mathrm{H}-\mathrm{NMR}(300 \mathrm{MHz}, \mathrm{MeOD}) \delta 8.58$ (s, 1H, H8), $8.53(\mathrm{~s}, 1 \mathrm{H}, \mathrm{H} 2), 6.55\left(\mathrm{t}, J=6.6 \mathrm{~Hz}, 1 \mathrm{H}, \mathrm{H} 1^{\prime}\right), 5.28$ $\left(\mathrm{d}, J=2.4 \mathrm{~Hz}, 2 \mathrm{H}, \mathrm{OCH}_{2}\right), 4.62-4.55\left(\mathrm{~m}, 1 \mathrm{H}, \mathrm{H}^{\prime}\right), 4.08\left(\mathrm{~m}, 1 \mathrm{H}, \mathrm{H} 4^{\prime}\right), 3.8\left(\mathrm{qd}, J=12.1,3.8 \mathrm{~Hz}, 2 \mathrm{H}, \mathrm{H} 5^{\prime}\right)$, $3.01(\mathrm{t}, J=2.4 \mathrm{~Hz}, 1 \mathrm{H}, \mathrm{CH}), 2.86\left(\mathrm{~m}, 1 \mathrm{H}, \mathrm{H} 2^{\prime} \mathrm{a}\right), 2.49$ (m, 1H, H2'b); ${ }^{13} \mathrm{C}-\mathrm{NMR}(75 \mathrm{MHz}, \mathrm{MeOD}) \delta 160.8$, $152.9,143.9,122.7,89.9,86.9,78.9,76.8,72.8,63.4,55.4,41.5$; HR-ESI MS ( $m / z):[\mathrm{M}+\mathrm{H}]^{+}$calculated for $\mathrm{C}_{13} \mathrm{H}_{15} \mathrm{~N}_{4} \mathrm{O}_{4}, 291.1087$; found 291.1088.

\subsubsection{6-N-Propynyl-3', $5^{\prime}$-O-bis(tert-butyldimethylsilyl)-2'-deoxyadenosine (28)}

To a stirred solution of $26(0.700 \mathrm{~g}, 1.46 \mathrm{mmol})$ in dry DCM $(50 \mathrm{~mL})$ was added $\mathrm{Et}_{3} \mathrm{~N}(0.61 \mathrm{~mL}$, $4.38 \mathrm{mmol}), \operatorname{TIBSCl}(1.325 \mathrm{~g}, 4.38 \mathrm{mmol})$ and DMAP (23 mg, $0.190 \mathrm{mmol})$ at rt under $\mathrm{N}_{2}$ atm. Following $48 \mathrm{~h}$ of reaction, the mixture was concentrated in vacuo and the residue was dissolved with EtOAc $(50 \mathrm{~mL})$ and water $(50 \mathrm{~mL})$. After separation of both layers, the aq. Layer was extracted with EtOAc $(3 \times 50 \mathrm{~mL})$. The combined organic layer was washed with water $(50 \mathrm{~mL})$ and brine $(50 \mathrm{~mL})$, dried over $\mathrm{Na}_{2} \mathrm{SO}_{4}$, filtered and evaporated under vacuum to get crude compound. The crude mixture was dissolved in EtOH $(50 \mathrm{~mL})$ to which was added propargylamine $(1.86 \mathrm{~mL}, 7.3 \mathrm{mmol})$ and DIPEA $(1.267 \mathrm{~mL}, 29.16 \mathrm{mmol})$ in a glass sealed tube at rt. The reaction mixture was slowly heated to $100{ }^{\circ} \mathrm{C}$ for $14 \mathrm{~h}$. After quenching with sat aq. $\mathrm{NaHCO}_{3}, \mathrm{EtOH}$ was removed under vacuum. The aqueous layer was extracted with EtOAc $(3 \times 50 \mathrm{~mL})$. The organic layer was washed with water and brine, dried over $\mathrm{Na}_{2} \mathrm{SO}_{4}$, and evaporated under vacuum. The residue was purified by flash silica gel chromatography (hexane:EtOAc = 6:4) to give $28(0.430 \mathrm{~g}, 57 \%)$ as a colorless oil. ${ }^{1} \mathrm{H}-\mathrm{NMR}\left(300 \mathrm{MHz}, \mathrm{CDCl}_{3}\right) \delta 8.45$ $(\mathrm{s}, 1 \mathrm{H}, \mathrm{H} 8), 8.13(\mathrm{~s}, 1 \mathrm{H}, \mathrm{H} 2), 6.46\left(\mathrm{t}, J=6.4 \mathrm{~Hz}, 1 \mathrm{H}, \mathrm{H} 1^{\prime}\right), 6.23(\mathrm{t}, J=5.6 \mathrm{~Hz}, 1 \mathrm{H}, \mathrm{NH}), 4.62(\mathrm{dt}, J=5.6$, $\left.3.8 \mathrm{~Hz}, 1 \mathrm{H}, \mathrm{H3}^{\prime}\right), 4.49$ (d, J = 2.5 Hz, 2H, $\left.\mathrm{NHCH}_{2}\right), 4.02\left(\mathrm{dd}, J=7.1,3.8 \mathrm{~Hz}, 1 \mathrm{H}, \mathrm{H}^{\prime}\right), 3.83(\mathrm{ddd}, J=14.4$, 11.2, 3.7 Hz, 2H, H5') 2.65 (dt, $\left.J=12.8,6.2 \mathrm{~Hz}, 1 \mathrm{H}, \mathrm{H} 2^{\prime} \mathrm{a}\right), 2.44$ (ddd, $J=13.0,6.1,3.8 \mathrm{~Hz}, 1 \mathrm{H}, \mathrm{H} 2^{\prime} \mathrm{b}$ ), $2.27(\mathrm{t}, J=2.5 \mathrm{~Hz}, 1 \mathrm{H}, \mathrm{CH}) ;{ }^{13} \mathrm{C}-\mathrm{NMR}\left(75 \mathrm{MHz}, \mathrm{CDCl}_{3}\right) \delta$ 153.6, 152.6, 148.7, 138.4, 120.0, 87.5, 84.0, $79.7,71.6,71.2,62.4,40.9,30.2,25.6,25.4,18.1,17.7,-5.0,-5.1,-5.7,-5.8 ;$ HR-ESI MS $(m / z):[\mathrm{M}+\mathrm{H}]^{+}$ calculated for $\mathrm{C}_{25} \mathrm{H}_{44} \mathrm{~N}_{5} \mathrm{O}_{3} \mathrm{Si}_{2}, 518.2977$; found 518.2969 [12].

\subsubsection{6-N-Propynyl-2'deoxyadenosine (8)}

To a stirred solution of $28(0.200 \mathrm{~g}, 0.386 \mathrm{mmol})$ in $\mathrm{MeOH}(15 \mathrm{~mL})$ was added $\mathrm{NH}_{4} \mathrm{~F}(0.143 \mathrm{~g}$, $3.86 \mathrm{mmol})$. The reaction mixture was slowly heated to $60-70{ }^{\circ} \mathrm{C}$ for $24 \mathrm{~h}$. The solvent was removed in vacuo, and the residue was purified by flash column chromatography on silica gel (MeOH:DCM = 1:9) to give the title compound $8(88 \mathrm{mg}, 75 \%)$ as a white solid. ${ }^{1} \mathrm{H}-\mathrm{NMR}(300 \mathrm{MHz}, \mathrm{MeOD}) \delta 8.31(\mathrm{~s}, 1 \mathrm{H}$, H8). 8.29 (s, 1H, H2), 6.45 (dd, $\left.J=7.9,6.0 \mathrm{~Hz}, 1 \mathrm{H}, \mathrm{H}^{\prime}\right), 4.64-4.55\left(\mathrm{~m}, 1 \mathrm{H}, \mathrm{H}^{\prime}\right), 4.42\left(\mathrm{~s}, 2 \mathrm{H}, \mathrm{NHCH}_{2}\right)$, $4.09\left(\mathrm{dd}, J=5.6,2.9 \mathrm{~Hz}, 1 \mathrm{H}, \mathrm{H}^{\prime}\right), 3.94-3.69\left(\mathrm{~m}, 2 \mathrm{H}, \mathrm{H} 5^{\prime}\right), 2.83\left(\mathrm{ddd}, J=13.6,7.9,6.0 \mathrm{~Hz}, 1 \mathrm{H}, \mathrm{H} 2^{\prime} \mathrm{a}\right)$, $2.62(\mathrm{t}, J=2.5 \mathrm{~Hz}, 1 \mathrm{H}, \mathrm{CH}), 2.42\left(\mathrm{ddd}, J=13.4,6.0,2.5 \mathrm{~Hz}, 1 \mathrm{H}, \mathrm{H} 2{ }^{\prime} \mathrm{b}\right) ;{ }^{13} \mathrm{C}-\mathrm{NMR}(75 \mathrm{MHz}, \mathrm{MeOD}) \delta$ $153.9,151.6,147.8,139.7,119.7,88.2,85.4,79.4,71.3,70.5,61.9,39.8,29.2 ;$ UV $\lambda_{\max }$ (nm): 265; HR-ESI MS $(m / z):[\mathrm{M}+\mathrm{H}]^{+}$calculated for $\mathrm{C}_{13} \mathrm{H}_{16} \mathrm{~N}_{5} \mathrm{O}_{3}, 290.1247$; found 290.1252 [12].

\subsubsection{1. $N^{1}$-Propynyl-3', $5^{\prime}$-O-bis(tert-butyldimethylsilyl)-2'-deoxyinosine (29)}

To a stirred solution of $26(0.800 \mathrm{~g}, 0.67 \mathrm{mmol})$ in dry THF $(30 \mathrm{~mL})$ was added triphenyl phosphine $(0.209 \mathrm{~g}, 0.8 \mathrm{mmol})$ at $\mathrm{rt}$ under $\mathrm{N}_{2}$ atm. After $30 \mathrm{~min}$ at rt, DEAD $(0.300 \mathrm{~mL}, 1.51 \mathrm{mmol})$ was added and the mixture was further stirred at $\mathrm{rt}$ for $6 \mathrm{~h}$. The crude reaction mixture was concentrated in vacuo, and purified by silica gel column chromatography (EtOAc:hexane $=4: 6)$ to give $29(0.681 \mathrm{mg}, 78 \%)$ as a white solid. ${ }^{1} \mathrm{H}-\mathrm{NMR}\left(300 \mathrm{MHz}, \mathrm{CDCl}_{3}\right) \delta 8.30(\mathrm{~s}, 1 \mathrm{H}, \mathrm{H} 8), 8.11(\mathrm{~s}, 1 \mathrm{H}, \mathrm{H} 2), 6.39(\mathrm{t}, J=6.4 \mathrm{~Hz}, 1 \mathrm{H}$, $\left.\mathrm{H}^{\prime}\right), 4.89\left(\mathrm{t}, J=2.8 \mathrm{~Hz}, 2 \mathrm{H}, \mathrm{OCH}_{2}\right), 4.61\left(\mathrm{dt}, J=5.7,3.6 \mathrm{~Hz}, 1 \mathrm{H}, \mathrm{H}^{\prime}\right), 4.03\left(\mathrm{dd}, J=6.9,3.3 \mathrm{~Hz}, 1 \mathrm{H}, \mathrm{H}^{\prime}\right)$, $3.81\left(\mathrm{qd}, J=11.2,3.6 \mathrm{~Hz}, 2 \mathrm{H}, \mathrm{H} 5^{\prime}\right), 2.60-2.50\left(\mathrm{~m}, 2 \mathrm{H}, \mathrm{H} 2^{\prime} \mathrm{b}, \mathrm{CH}\right), 2.43(\mathrm{ddd}, J=13.1,6.1,3.9 \mathrm{~Hz}, 1 \mathrm{H}$, $\left.\mathrm{H}_{2}^{\prime} \mathrm{a}\right), 0.93$ (s, 9H, $\left.\mathrm{SiC}\left(\mathrm{CH}_{3}\right)_{3}\right), 0.92\left(\mathrm{~s}, 9 \mathrm{H}, \mathrm{SiC}\left(\mathrm{CH}_{3}\right)_{3}\right), 0.12\left(\mathrm{~s}, 6 \mathrm{H}, \mathrm{SiC}\left(\mathrm{CH}_{3}\right)_{2}\right), 0.10\left(\mathrm{~s}, 3 \mathrm{H}, \mathrm{SiCH}_{3}\right), 0.09$ $\left(\mathrm{s}, 3 \mathrm{H}, \mathrm{SiCH}_{3}\right) ;{ }^{13} \mathrm{C}-\mathrm{NMR}\left(75 \mathrm{MHz}, \mathrm{CDCl}_{3}\right) \delta 155.5,146.7,145.5,138.0,124.1,87.7,83.9,76.3,75.2,71.5$, $62.4,41.3,34.6,25.6,25.4,18.1,17.7,-5.0,-5.1,-5.7,-5.8$; HR-ESI MS $(m / z):[\mathrm{M}+\mathrm{H}]^{+}$calculated for $\mathrm{C}_{25} \mathrm{H}_{43} \mathrm{~N}_{4} \mathrm{O}_{4} \mathrm{Si}_{2}, 519.2817$; found 519.2844. 


\subsubsection{2. $N^{1}$-Propynyl-2'deoxyinosine (10)}

To a stirred solution of $29(0.620 \mathrm{~g}, 1.19 \mathrm{mmol})$ in $\mathrm{MeOH}(30 \mathrm{~mL})$ was added $\mathrm{NH}_{4} \mathrm{~F}(0.442 \mathrm{~g}$, $11.2 \mathrm{mmol}$ ) at $\mathrm{rt}$. The reaction mixture was slowly heated to $60-70{ }^{\circ} \mathrm{C}$ for $24 \mathrm{~h}$. The solvent was removed in vacuo, and the residue was purified by flash column chromatography on silica gel (MeOH:DCM = 1:9) to give the title compound $10(0.279 \mathrm{~g}, 80 \%)$ as a white solid. ${ }^{1} \mathrm{H}-\mathrm{NMR}(300 \mathrm{MHz}$, MeOD) $\delta 8.43(\mathrm{~s}, 1 \mathrm{H}, \mathrm{H} 8), 8.33(\mathrm{~s}, 1 \mathrm{H}, \mathrm{H} 2), 6.41\left(\mathrm{t}, J=6.6 \mathrm{~Hz}, 1 \mathrm{H}, \mathrm{H} 1^{\prime}\right), 4.91(\mathrm{~d}, J=2.4 \mathrm{~Hz}, 2 \mathrm{H}$, $\left.\mathrm{OCH}_{2}\right), 4.65-4.50\left(\mathrm{~m}, 1 \mathrm{H}, \mathrm{H}^{\prime}\right), 4.05\left(\mathrm{dd}, J=6.8,3.4 \mathrm{~Hz}, 1 \mathrm{H}, \mathrm{H} 4^{\prime}\right), 3.79\left(\mathrm{qd}, J=12.1,3.8 \mathrm{~Hz}, 2 \mathrm{H}, \mathrm{H} 5^{\prime}\right)$, $2.94(\mathrm{t}, J=2.4 \mathrm{~Hz}, 1 \mathrm{H}, \mathrm{CH}), 2.74\left(\mathrm{dt}, J=13.3,6.6 \mathrm{~Hz}, 1 \mathrm{H}, \mathrm{H2}{ }^{\prime} \mathrm{a}\right), 2.49(\mathrm{ddd}, J=13.5,6.2,3.5 \mathrm{~Hz}, 1 \mathrm{H}$, $\left.\mathrm{H} 2{ }^{\prime} \mathrm{b}\right) ;{ }^{13} \mathrm{C}-\mathrm{NMR}(75 \mathrm{MHz}, \mathrm{MeOD}) \delta$ 155.6, 147.0, 146.8, 139.4, 123.3, 87.9, 84.6, 76.7, 74.1, 70.8, 61.5, 40.0, 34.7; UV $\lambda_{\max }(\mathrm{nm}): 250$; HR-ESI MS $(m / z)$ : $[\mathrm{M}+\mathrm{H}]^{+}$calculated for $\mathrm{C}_{13} \mathrm{H}_{14} \mathrm{~N}_{4} \mathrm{O}_{4} \mathrm{Na}$, 313.0907; found 313.0912 .

\subsection{Cell Viability Assay}

An amount of $3 \times 10^{4}$ MT4 cells were seeded per well in a 96-well plate. In order to determine the concentration killing $50 \%$ of the MT- 4 cells (the $50 \%$ cytotoxic concentration, $\mathrm{CC}_{50}$ ), the cells were incubated with a dilution series of the nucleoside analogues. In order to determine the concentration achieving $50 \%$ protection against $\mathrm{HIV}$ (the $50 \%$ effective concentration, $\mathrm{EC}_{50}$ ), cells were pre-incubated with a dilution series of the nucleoside analogues for one hour, before they were infected with a fivefold dilution of HIV-1 IIIB virus using an MOI of 0.01 , together with the respective analogues. Five days after incubation and infection, the viability was examined with the MTT method. [22] Briefly, $20 \mu \mathrm{L}$ of a freshly prepared MTT stock solution $(7.5 \mathrm{mg} / \mathrm{mL}$ in PBS, Sigma-Aldrich, Overijse, Belgium) was added to each well to a final volume of $220 \mu \mathrm{L}$. After one hour of incubation at $37^{\circ} \mathrm{C}$, the medium was carefully removed and the purple formazan crystals were solubilized by the addition of $10 \%$ triton in acidified isopropanol (0.4\% methanesulfonic acid, Sigma Aldrich). The OD was measured at $540 \mathrm{~nm}$ with an EnVision 2130 Multilabel Plate Reader (PerkinElmer, Zaventem, Belgium). Data were calculated using the median OD value of three wells. All experiments were performed in triplicate with the table displaying the average for EdU and the lowest CC50 values as found for the propargylated compounds, respectively.

\section{Conclusions}

A series of propargyl-modified purine 2'-deoxynucleosides was successfully synthesized in an effort to develop clickable nucleosides for selective incorporation into and visualization of HIV cDNA. All compounds were devoid of cellular toxicity, and did not inhibit HIV replication, prior requirements for a successful click nucleoside for in vivo visualization techniques. The validity of the idea and the potential for selective staining was briefly shown in this paper. The individual evaluation of the various new clickable analogues as potential selective reporter molecule will be communicated elsewhere. We also believe these clickable nucleosides will find use for various other applications.

Supplementary Materials: The following are available online, ${ }^{1} \mathrm{H}$ and ${ }^{13} \mathrm{C}-\mathrm{NMR}$ spectra and MS analytical spectra: SI-Spectra Propargyl Project.docx.

Author Contributions: A.V.A. (chemical part) and Z.D. (biological part) conceived and designed the experiments; A.V., S.R.P. and F.D.W. performed the experiments; E.L. provided support for NMR measurements; A.V.A. largely wrote the manuscript with input of all others. All authors read and approved the final manuscript.

Funding: This work was supported by the Research Fund Flanders [Fonds voor Wetenschappelijk Onderzoek, G077814N and G0A5316N] and by a KU Leuven C1 grant C14/17/095. FDW is grateful for a personal fellowship from the same fund [grant No. FWO $1110216 \mathrm{~N}$ ]. Mass spectrometry was made possible by the support of the Hercules Foundation of the Flemish Government [20100225E7].

Acknowledgments: We are indebted to Jef Rozenski for providing MS analysis and to Chantal Biernaux for final typesetting.

Conflicts of Interest: The authors declare no conflict of interest. 


\section{References}

1. Johnson, I.; Spence, M.T.Z. Molecular Probes Handbook: A Guide to Fluorescent Probes and Labeling Technologies; Life Technologies: New York, NY, USA, 2010.

2. Sauer, M.; Hofkens, J.; Enderlein, J. Handbook of Fluorescence Spectroscopy and Imaging: From Single Molecules to Ensembles; Wiley-VCH Verlag GmbH \& Co. KgaA: Weinheim, Germany, 2011.

3. Sherer, N.M.; Lehmann, M.J.; Jimenez-Soto, L.F.; Ingmundson, A.; Horner, S.M.; Cicchetti, G.; Allen, P.G.; Pypaert, M.; Cunningham, J.M.; Mothes, W. Visualization of retroviral replication in living cells reveals budding into multivesicular bodies. Traffic 2003, 4, 785-801. [CrossRef] [PubMed]

4. Close, D.M.; Xu, T.T.; Sayler, G.S.; Ripp, S. In vivo bioluminescent imaging (BLI): Noninvasive visualization and interrogation of biological processes in living animals. Sensors 2011, 11, 180-206. [CrossRef] [PubMed]

5. Jackson, D.A.; Pombo, A. Replicon clusters are stable units of chromosome structure: Evidence that nuclear organization contributes to the efficient activation and propagation of s phase in human cells. J. Cell Biol. 1998, 140, 1285-1295. [CrossRef] [PubMed]

6. Kennedy, B.K.; Barbie, D.A.; Classon, M.; Dyson, N.; Harlow, E. Nuclear organization of DNA replication in primary mammalian cells. Genes Dev. 2000, 14, 2855-2868. [CrossRef]

7. Salic, A.; Mitchison, T.J. A chemical method for fast and sensitive detection of DNA synthesis in vivo. Proc. Natl. Acad. Sci. USA 2008, 105, 2415-2420. [CrossRef] [PubMed]

8. Lentz, S.I.; Edwards, J.L.; Backus, C.; McLean, L.L.; Haines, K.M.; Feldman, E.L. Mitochondrial DNA (mtDNA) biogenesis: Visualization and duel incorporation of BrdU and EdU into newly synthesized mtDNA in vitro. J. Histochem. Cytochem. 2010, 58, 207-218. [CrossRef]

9. Qu, D.; Wang, G.; Wang, Z.; Zhou, L.; Chi, W.; Cong, S.; Ren, X.; Liang, P.; Zhang, B. 5-ethynyl-2'-deoxycytidine as a new agent for DNA labeling: Detection of proliferating cells. Anal. Biochem. 2011, 417, 112-121. [CrossRef]

10. Ligasová, A.; Liboska, R.; Friedecký, D.; Mičová, K.; Adam, T.; Oždian, T.; Rosenberg, I.; Koberna, K. Dr Jekyll and Mr Hyde: A strange case of 5-ethynyl-2'-deoxyuridine and 5-ethynyl-2'-deoxycytidine. Open Biol. 2016, 6, 150172. [CrossRef]

11. Borrenberghs, D.; Dirix, L.; De Wit, F.; Rocha, S.; Blokken, J.; De Houwer, S.; Gijsbers, R.; Christ, F.; Hofkens, J.; Hendrix, J.; et al. Dynamic oligomerization of integrase orchestrates HIV nuclear entry. Sci. Rep. 2016, 6, 1-14. [CrossRef]

12. Matuszewski, M.; Kiliszek, A.; Rypniewski, W.; Lesnikowski, Z.J.; Olejniczak, A.B. Nucleoside bearing boron clusters and their phosphoramidites-building blocks for modified oligonucleotide synthesis. New J. Chem. 2015, 39, 1202-1221. [CrossRef]

13. Jiang, H.; Congleton, J.; Liu, Q.; Merchant, P.; Malavasi, F.; Lee, H.C.; Hao, Q.; Yen, A.; Lin, H. Mechanism-based small molecule probes for labeling cd38 on live cells. J. Am. Chem. Soc. 2009, 131, 1658-1659. [CrossRef] [PubMed]

14. Ghanty, U.; Fostvedt, E.; Valenzuela, R.; Beal, P.A.; Burrows, C.J. Promiscuous 8-alkoxyadenosines in the guide strand of an SiRNA: Modulation of silencing efficacy and off-pathway protein binding. J. Am. Chem. Soc. 2012, 134, 17643-17652. [CrossRef] [PubMed]

15. Western, E.C.; Shaughnessy, K.H. Inhibitory effects of the guanine moiety on Suzuki couplings of unprotected halonucleosides in aqueous media. J. Org. Chem. 2005, 70, 6378-6388. [CrossRef] [PubMed]

16. Münzel, M.; Szeibert, C.; Glas, A.F.; Globisch, D.; Carell, T. Discovery and synthesis of new UV-induced intrastrand c(4-8)g and g(8-4)c photolesions. J. Am. Chem. Soc. 2011, 133, 5186-5189. [CrossRef] [PubMed]

17. Böge, N.; Gräsl, S.; Meier, C. Synthesis and properties of oligonucleotides containing c8-deoxyguanosine arylamine adducts of borderline carcinogens. J. Org. Chem. 2006, 71, 9728-9738. [CrossRef]

18. Torraca, K.E.; Huang, X.; Parrish, C.A.; Buchwald, S.L. An efficient intermolecular palladium-catalyzed synthesis of aryl ethers. J. Am. Chem. Soc. 2001, 123, 10770-10771. [CrossRef] [PubMed]

19. Dumas, A.; Luedtke, N.W. Site-specific control of N7-metal coordination in DNA by a fluorescent purine derivative. Chem. A Eur. J. 2012, 18, 245-254. [CrossRef] [PubMed]

20. Taniguchi, Y.; Fukabori, K.; Kikukawa, Y.; Koga, Y.; Sasaki, S. 2,6-diaminopurine nucleoside derivative of 9-ethyloxy-2-oxo-1,3-diazaphenoxazine (2-amino-adap) for recognition of 8-oxo-dg in DNA. Biorg. Med. Chem. 2014, 22, 1634-1641. [CrossRef] 
21. Kokatla, H.P.; Lakshman, M.K. One-pot etherification of purine nucleosides and pyrimidines. Org. Lett. 2010, 12, 4478-4481. [CrossRef]

22. Szucs, G.; Melnick, J.L.; Hollinger, F.B. A simple assay based on HIV infection preventing the reclustering of mt-4 cells. Bull. World Health Organ. 1988, 66, 729-737.

23. Szombati, Z.; Baerns, S.; Marx, A.; Meier, C. Synthesis of c8-arylamine-modified 2'-deoxyadenosine phosphoramidites and their site-specific incorporation into oligonucleotides. ChemBioChem 2012, 13, 700-712. [CrossRef]

24. Holzberger, B.; Strohmeier, J.; Siegmund, V.; Diederichsen, U.; Marx, A. Enzymatic synthesis of 8-vinyl- and 8-styryl-2'-deoxyguanosine modified DNA-Novel fluorescent molecular probes. Bioorg. Med. Chem. Lett. 2012, 22, 3136-3139. [CrossRef] [PubMed]

25. Onizuka, K.; Taniguchi, Y.; Sasaki, S. A new odorless procedure for the synthesis of 2'-deoxy-6-thioguanosine and its incorporation into oligodeoxynucleotides. Nucleosides Nucleotides Nucleic Acids 2009, 28, 752-760. [CrossRef] [PubMed]

26. Buff, M.C.; Schäfer, F.; Wulffen, B.; Müller, J.; Pötzsch, B.; Heckel, A.; Mayer, G. Dependence of aptamer activity on opposed terminal extensions: Improvement of light-regulation efficiency. Nucleic Acids Res. 2010, 38, 2111-2118. [CrossRef] [PubMed]

Sample Availability: Samples of the compounds are not available from the authors. 